
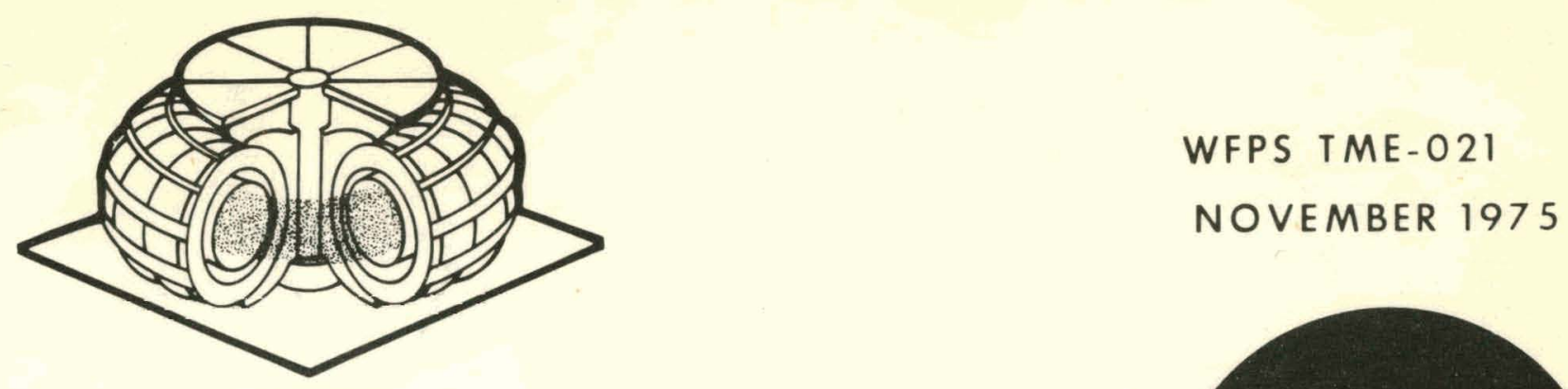

Westinghouse Electric Corporation Fusion Power Systems Department

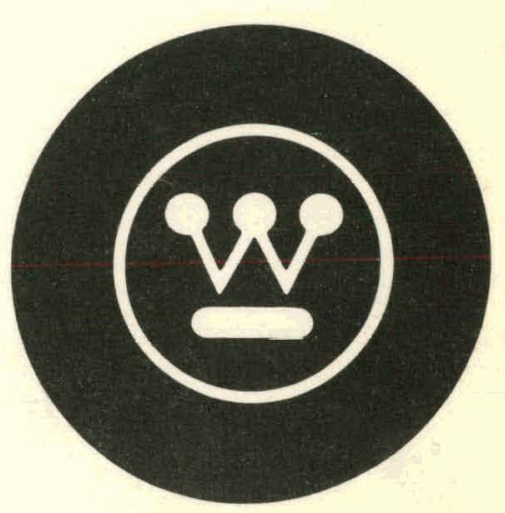

MASTER

\title{
TFTR VACUUM SYSTEM CONSIDERATIONS
}




\section{DISCLAIMER}

This report was prepared as an account of work sponsored by an agency of the United States Government. Neither the United States Government nor any agency Thereof, nor any of their employees, makes any warranty, express or implied, or assumes any legal liability or responsibility for the accuracy, completeness, or usefulness of any information, apparatus, product, or process disclosed, or represents that its use would not infringe privately owned rights. Reference herein to any specific commercial product, process, or service by trade name, trademark, manufacturer, or otherwise does not necessarily constitute or imply its endorsement, recommendation, or favoring by the United States Government or any agency thereof. The views and opinions of authors expressed herein do not necessarily state or reflect those of the United States Government or any agency thereof. 


\section{DISCLAIMER}

Portions of this document may be illegible in electronic image products. Images are produced from the best available original document. 


\section{TFTR VACUUM SYSTEM CONSIDERATIONS}

Prepared by: W. J. Lange, J. G. Gorman

D. Green, and D. A. Sink

Approved by:

T. C. Varlien

Engineering Manager

TFTR Project

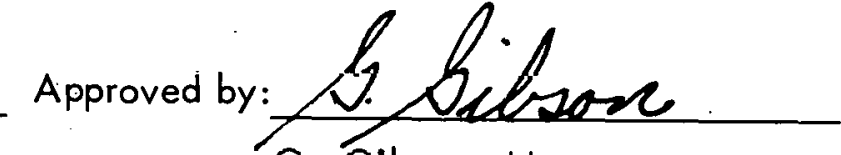

G. Gibson, Manager

Applied Physics

TFTR Project

\section{WESTINGHOUSE ELECTRIC CORPORATION \\ FUSION POWER SYSTEMS DEPARTMENT \\ P. O. BOX 10864 \\ PITTSBURGH, PENNSYLVANIA 15236}

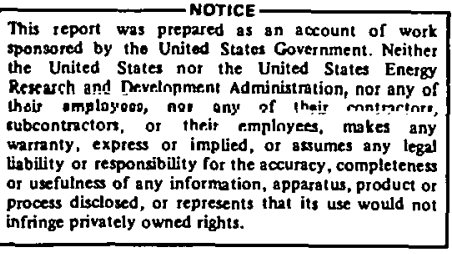


The Tokamak Fusion Test Reactor (TFTR) vacuum system has been designed using conventional ultrahigh vacuum (UHV) components and technology. This report describes the rationale and motivation that went into its design. Mercury diffusion pumps were selected over other existing high vacuum pumps. A system of four pumps is designed to provide a base pressure of $\leq 8 \times 10^{-6} \mathrm{~Pa}$ and a low impurity level within the torus. These features will be accomplished without in situ bakeout, but the system will be pre-baked before final assembly and periodically discharge cleaned during operation. Bakeout of the total vacuum system has been omitted in the initial design because it is believed that satisfactory conditions of the walls can be obtained without it. However, bakeout is being considered as a design alternative.

Calculated spectra of mass to charge $(M / e)$ ratios obtained from the residual gas analyzers (RGA's) to be used in the vacuum system forelines are presented. These spectra indicate the ability of the RGA's to monitor the tritium content of the vacuum system. The requirements for vacuum seals on TFTR are enumerated and the reasons for selecting flat copper washer seals are giver. Alsu included is a brlef summary of initial experimental studies on the $\mathrm{Zr} / \mathrm{Al}$-type getters to be used to pump hydrogen isotopes. The report. concludes with a discussion of in situ bakeout, a method of reaching bakeout temperatures, and problems related to such operations. 


\section{ACKNOWLEDGEMENT}

We are grateful for the help and advice received from Dr. Jack H. Singleton. Special acknow ledgement should go to Princeton Plasma Physics Laboratory (PPPL) which has been under contract by ERDA to design TFTR. . Comments and discussions with Drs. E. D. Meservey, G. Lewin, D. H. Mullaney and others at PPPL have provided much of the insight necessary for the development of the TFTR vacuum system. We greatly appreciate the technical assistance of J. R. Auld in conducting the $\mathrm{Zr} / \mathrm{Al}$ getter experiments.

This work was supported by U. S. Energy Research and Development Administration Contract E (11-1)-3073 and Subcontract 192 thereto. Reproduction, translation, publication, use and disposal, in whole or in part, by or for the United States Government is permitted.

\section{LEGAL NOTICE}

This report was prepared as an account of Government sponsored:work. Neither the United States, nor the Administration, nor any person acting on behalf of the Administration:

A... Makes any warranty or representation, express: or implied, with respect to the accuracy, completeness, or usefulness of the information contained in this report, or that the use of any information, apparatus, method or process disclosed in this report may not infringe privately owned rights; or

B. Assumes any liabilities with respect to the use of, or for damages: resulting from the use of any information, apparatus, method, or process disclosed in this report.
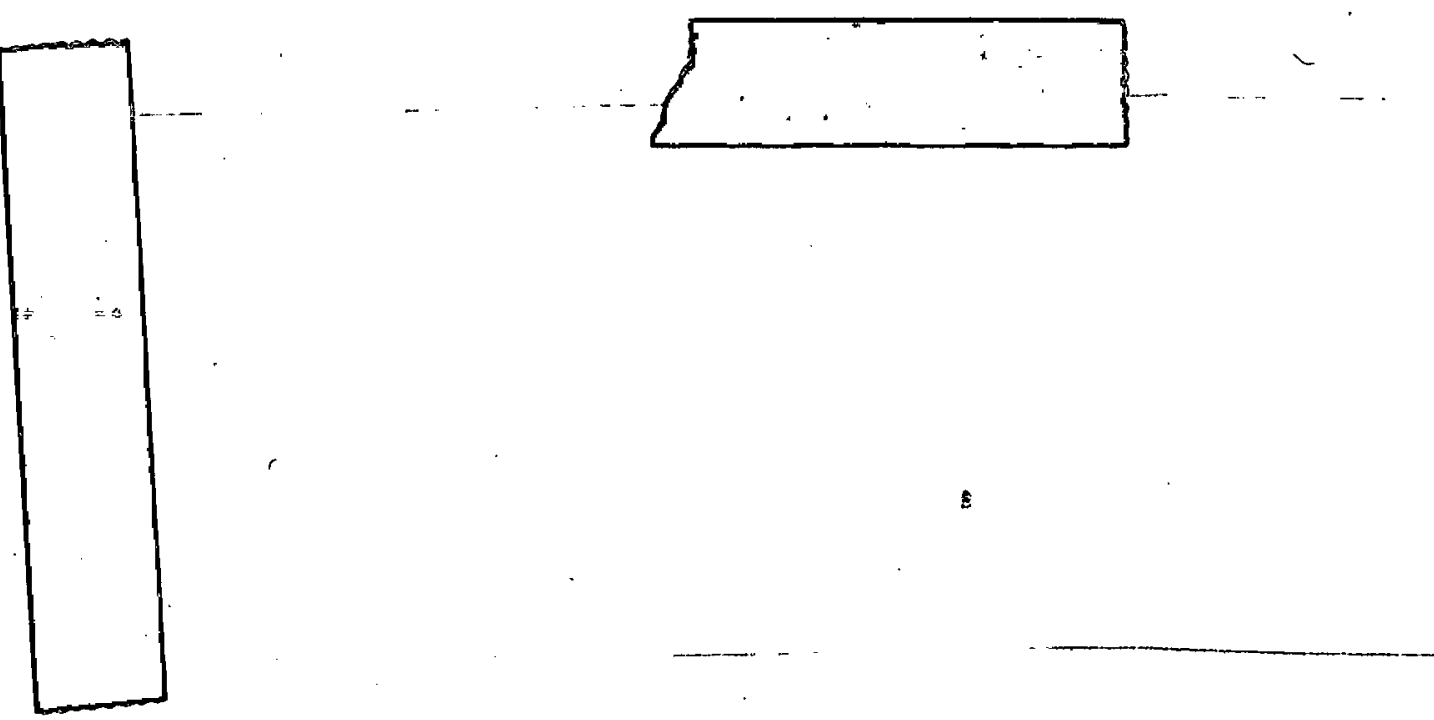


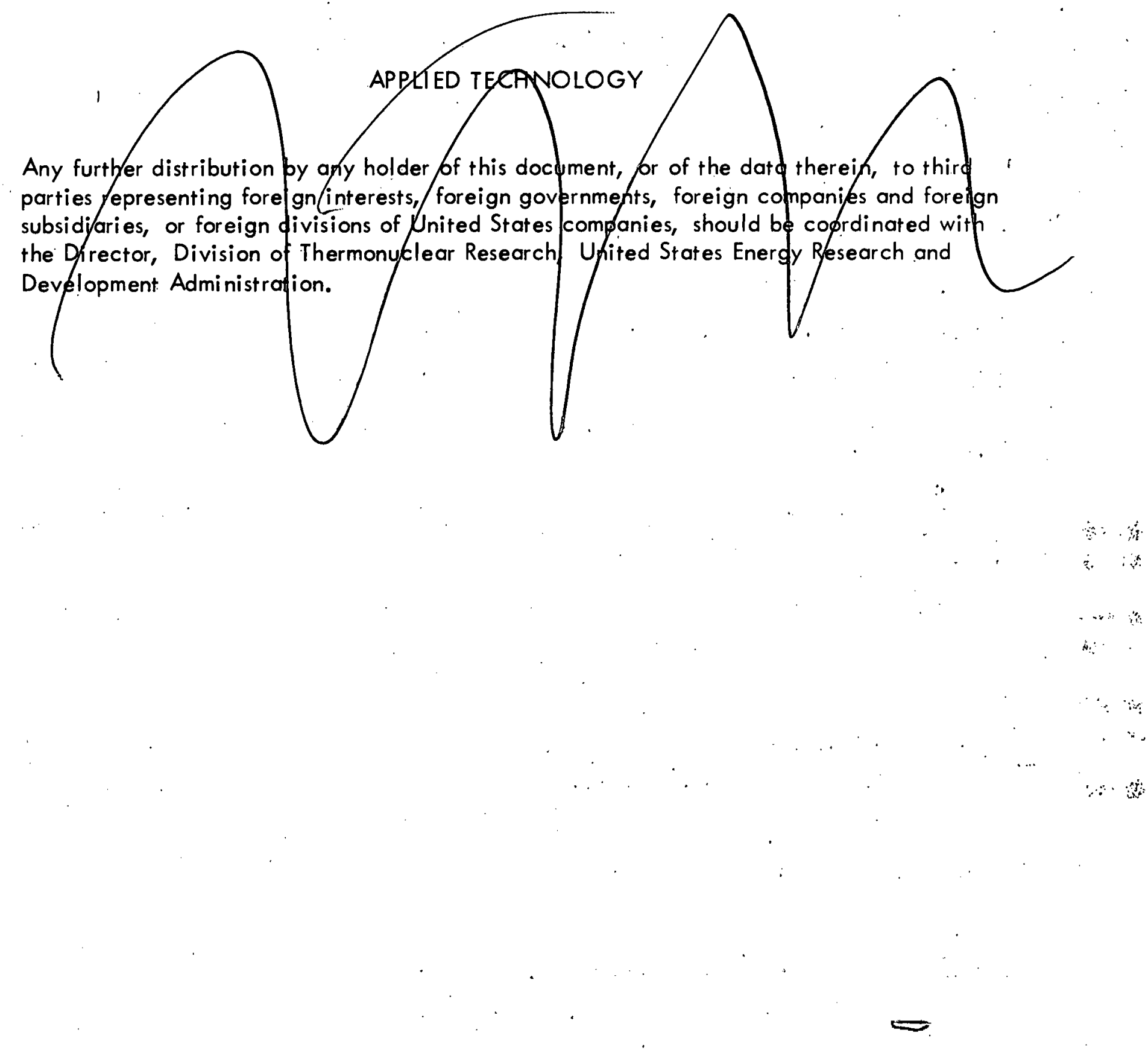




\section{TABLE OF CONTENTS}

1.0 INTRODUCTION

$\frac{\text { Page }}{1}$

2.0 DESCRIPTION OF THE TFTR VACUUM SYSTEM

3.0 TFTR VACUUM SYSTEM OPERATION

3.1. Base Pressure Considerations * 10

3.2 Pumpout and Fill Times 11

3.3 Monitoring the Forelines Using Residual Gas Analyzers 13

4.0 VACUUM SEALS $\quad 22$

4.1 Basic Considerations 22

4.2 Criteria for the Selection of Vacuum System Seals 23

4.3 Comparison of Metal Gasketed Seals 25

5.0 ZIRCONIUM - ALUMINUM GETTERS 26

$5.1 \quad$ Getter Characteristics 26

5.2 Status of the Initial $\mathrm{Zr} / \mathrm{Al}$ Getter Study 28

6.0 IN SITU BAKEOUT

6.1 Discussion 31

6.2 A Method of Reaching Bakeout Temperatures 32

6.3 Problems Related to In Situ Bakeout 33

$\begin{array}{lll}7.0 & \text { SUMMARY } & 36\end{array}$

References 


\section{LIST OF FIGURES}

Figure No.

Title

$\underline{\text { Page }}$

2.0-1

The Tokamak Fusion Test Reactor

Schematic of Mechanical Pumping Unit

Schematic of Tritium Holding and Cleanup Unit

Block Diagram of Torus Pumping System Showing One of the Four High Vacuum Pumping Stacks and Associated Backing System

The Location of the Diffusion Pumps on the TFTR Vacuum Vessel Neutral Beam Injection of Deuterium Neutral Beam Injection of Deuterium 


\section{LIST OF TABLES}

Table No.

2.0-1

$3.3-1$

4.1-1

$7.0-1$
Title

Torus Vacuum Pumping System Design Summary

Tabulation of the Relative Peak Heights Shown in Figure 2.3-1

Port Seals for TFTR.

Tablulation of Important Parameters for the TFTR Vacuum System $\underline{\text { Page }}$

2 .

18

24

38 


\subsection{INTRODUCTION}

This report presents a summary of a number of studies that have provided the basis for the conceptual design of the TFTR vacuum system. This design represents a reference point in arriving at the final TFTR design, and is described in detail in Volume II of the TFTR Final Conceptual Design Report. The purpose of this report is to provide the rationale and motivation that went into this specific design of the vacuum system.

The design and construction of the vacuum system must be carefully considered if the goal of controlling impurity concentration in TFTR is to be realized. The degree of care that must be taken cannot be over-emphasized. A particularly appropriate philosophy for the design of ultraclean and ultrahigh vacuum systems is given in Reference. 1 . There is a wealth of information available on UHV in standard texts, ${ }^{(2)}$ as well as the Transactions of the National Vacuum Symposium and journals devoted to vacuum science and technology and reports from the field of fusion technology. A guide to this literature and to less widely circulated information $^{(3)}$ is best sought from those trained in the art. One "non-UHV quality" component that finds its way into the vacuum system could delay successful operation of TFTR for weeks, if not months. A series of such components exhibiting high outgassing or high vapor pressure that cannot readily be determined and located after the machine is placed into operation could very well compromise the physics goals of TFTR (cf. section 2.1, Volume 1, TFTR Final Conceptual Design Report).

This paper is divided into five sections as follows: 1) a brief description of the TFTR vacuum system, 2) the operation of this vacuum system, 3) the considerations that went into selecting the vacuum seals, 4) the $\mathrm{Zr} / \mathrm{Al}$ gettering system, and 5) a discussion of in situ bakeout. The final section of this report is a summary and includes a table listing the main parameters of the TFTR vacuum system.

\subsection{DESCRIPTION OF THE TFTR VACUUM SYSTEM}

The TFTR vacuum system comprises the toroidal vacuum vessel, the vacuum pumping system from the pumping ports on the vessel back through the pumping lines, valves and traps, the neutral 
beam lines back through the first "effective trap", and all appendages to the toroidal vessel such as diagnostic arms, etc. In other words, any volume or component that is in communication with the main vacuum vessel that can contribute impurities to the discharge is regarded as part of the vacuum system. The TFTR; showing the toroidal vacuum vessel, one of the highvacuum pumps, and the neutral beam injection ducts, is represent in Fig. 2.0-1.

The vacuum vessel encloses a toroidal volume, $64 \mathrm{~m}^{3}$, which has a $2.65 \mathrm{~m}$ major radius and a $1.10 \mathrm{~m}$ minor radius. The torus is formed from straight hollow pipe sections which are joined alternately by stiffening rings and bellows for a total exposed surface area of $1000 \mathrm{~m}^{2}$. The vessel will be fabricated using austenitic 305 stainless steel as the primary material, and using Nitronic 33, OFHC copper, tungsten,molybdenum, and ceramic componentśs. Approximately 250 ports interfacing diagnostic equipment, neutral beam lines, and the pumping system will be attached directly to the vessel. Each port will have a hard-sealed isolation valve, and,when auxiliary vacuum pumping units are employed, oil-free systems will be used. The main high vacuum pumping will be performed by four $61-\mathrm{cm}$ diameter mercury diffusion pumps; each of which is connected through a duct, a UHV valve, and a cold trap/baffle in series. The total effective pumping speed for $\mathrm{H}_{2}$ for this combination of pumps is approximately $33 \mathrm{~m} / \mathrm{s}$. A summary of the pumping system design features is given in Table 2.0-1.

\section{TABLE $\quad 2.0-1$}

\section{TORUS VACUUM PUMPING SYSTEM DESIGN SUMMARY}

- $\quad 4-61 \mathrm{~cm}$ Diameter Diffusion Pumps

- An UHV Valve and Cold Trap at $\leq 148 \mathrm{~K}$ Above Each Diffusion Pump

- Diffusion Pump Stack Designed for Remote Maintenance

- A Total Pumping Speed for Hydrogen of $33 \mathrm{~m} / \mathrm{s}$ for the Four Diffusion Pumps

- Diffusion Pump Stack of Non-Magnetic and Nuclear Radiation Resistant Materials

- Pumpout e-Folding Time of $<10 \mathrm{sec}$

- Base Pressure $<8 \times 10^{-6} \mathrm{~Pa}$ 
- Pre-Bakeout at $775 \mathrm{~K}$ for $2 \times 10^{5} \mathrm{sec}$ (60 hours) of Components Above Diffusion Pumps

- Discharge Cleaning

- Closed Backing System

- 4 - Mechanical Backing Pumps with Zeolite Traps for Removal of Non-Hydrogen Gases

- Mechanical Pumps Discharge Into $0.1 \mathrm{~m}^{3}$ Ballast Tanks

- $\quad 8-\mathrm{Zr} / \mathrm{Al}$ Canister Units for. Removal of Hydrogen Gases Including "Cracker" to Breakdown Hydrocarbons

- Pumping Speed of $0.13 \mathrm{~m}^{3} / \mathrm{s}$ for Four Mechanical Pumps

- Rough Down Time of $1.8 \times 10^{4} \mathrm{~s}$ (5 hours)

- $\quad 2$ - Residual Gas Analyzers with Resolving Power $\geqq 50$, with Adjustable Scanning Speeds, and with Partial Pressure Sensitivity $\leq 10^{-8} \mathrm{~Pa}$

- 2 - Tritium Monitors for Checking Tritium Content in Ballast Tanks

- Interface with Tritium Cleanup System to Treat. Mechanical Pump Exhaust

- Foreline and Backing System Located in Basement Below Test Cell

- All Hard (Metal) Seals

- Outgassing Rate $10^{-7} \mathrm{~Pa} \mathrm{~m}^{3} / \mathrm{s} \mathrm{m}^{2}$

- Ultrahigh Vacuurn (UHV) Standards

- Protective Interlock Systems

- Local and Central Control and Monitoring Systems for Automatic and Manual Operations

- Service Life of 8 years

Backing each pump will be a mechanical pump having a zeolite trap on its inlet side. Above this trap is a dry $\mathrm{N}_{2}$ feed to be used when returning the torus to atmospheric pressure and during reactivation of the zeolite trap. A demister on the exhaust line from the mechani- 
cal pump presents oil vapor from reaching the tritium cleanup unit. A schematic of this arrangement is shown in Figure 2.0-2.

The exhaust from each mechanical pump is either vented to the atmosphere or valved to the Tritium Cleanup System through a ballast tank. A schematic of a tritium holding and cleanup unit is shown in Fig. 2.0-3. The connecting lines to and from the vacuum vessel will be used when the contents of the Torus Vacuum Vessel are cycled through the cleanup unit without being pumped by the mechanical pumps in the forelines. This cycling process will be employed if the situation arises in which the vacuum vessel is at atmospheric pressure while containing tritium at a level too high to be exhausted directly to the atmosphere. Thus, by cycling the contents through the cleanup unit, the tritium level will be reduced to an acceptable level before the main vessel is roughed-down.

In addition to the mechanical pumping unit, each high-vacuum pump will be backed by a set of regenerable $\mathrm{Zr} / \mathrm{Al}$ gettering units for pumping hydrogen isotopes and compounds. Compounds such as methane are fragmented by "crackers" located in each getter canister and then the gaseous hydrogen by-products are gettered by conversion into a metallic solution in the $\mathrm{Zr} / \mathrm{Al}$ alloy. A unit is schematically represented in Fig. 2.0-4. Only one of the two canisters backs the diffusion pump at a time. The second canister is a reserve unit. Each of these canisters contains four getter cartridges and a cracker in the form of hot-tungsten filaments. There is a third canister per foreline (not shown) to be used as a replacement during the periods in which a canister is regenerated.

The backing system includes residual gas analyzers (RGA's) to monitor the content of the forelines during normal operations and the arrival of argon, helium, or other tracer gases during leak checking procedures. An RGA services a pair of forelines and communicates with them through an automatic pressure-regulating UHV valve. A block diagram of a high-vacuum pumping stack and associated fore-vacuum system is shown in Figure 2.0-5. The piping from the "2nd foreline" shows the interfacing of another foreline system with the RGA unit and the tritium holding and cleanup unit. There are two RGA units on the pumping system which consists of four independent forelines. 


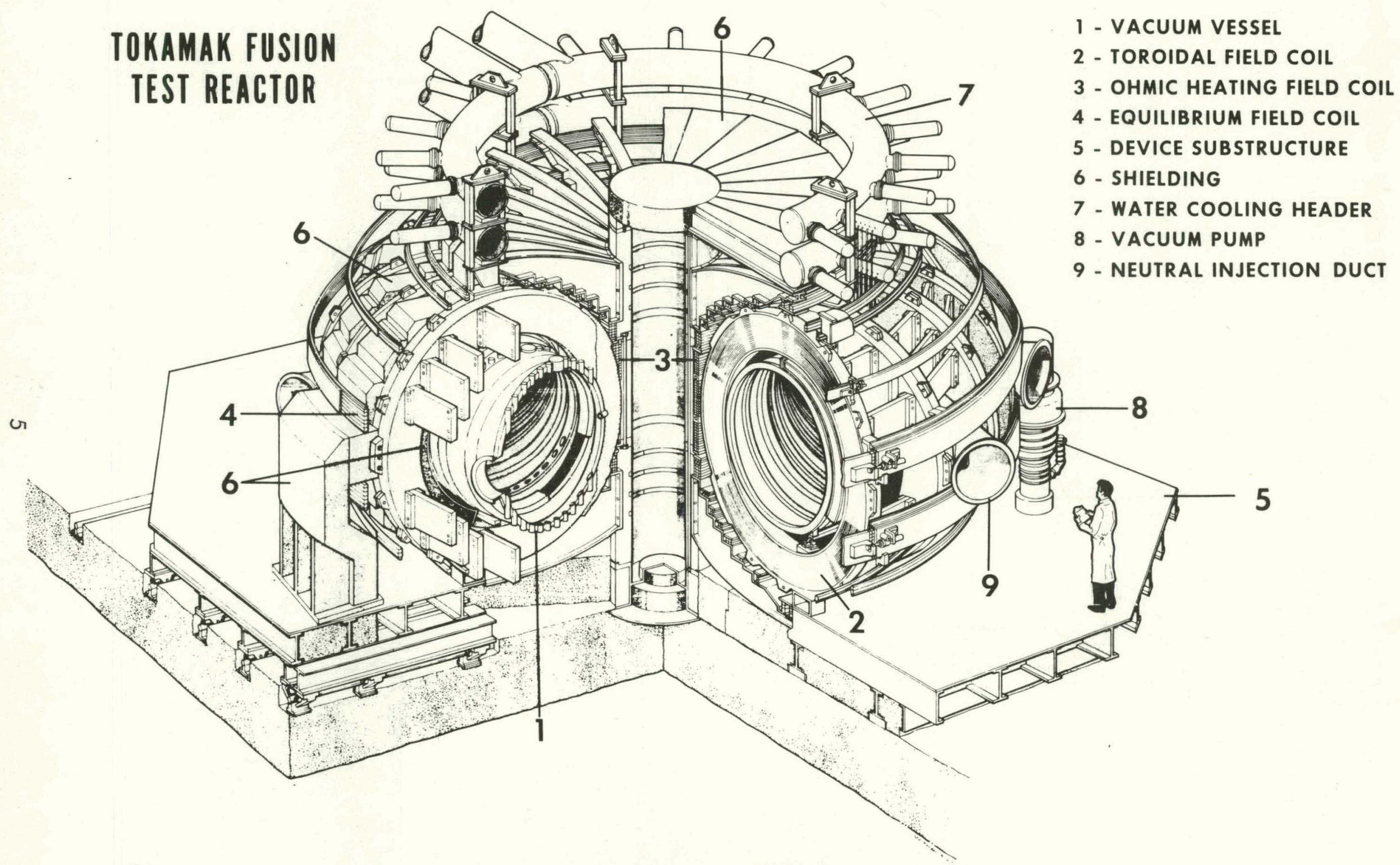

Figure 2.0-1 The Tokamak Fusion Test Reactor 


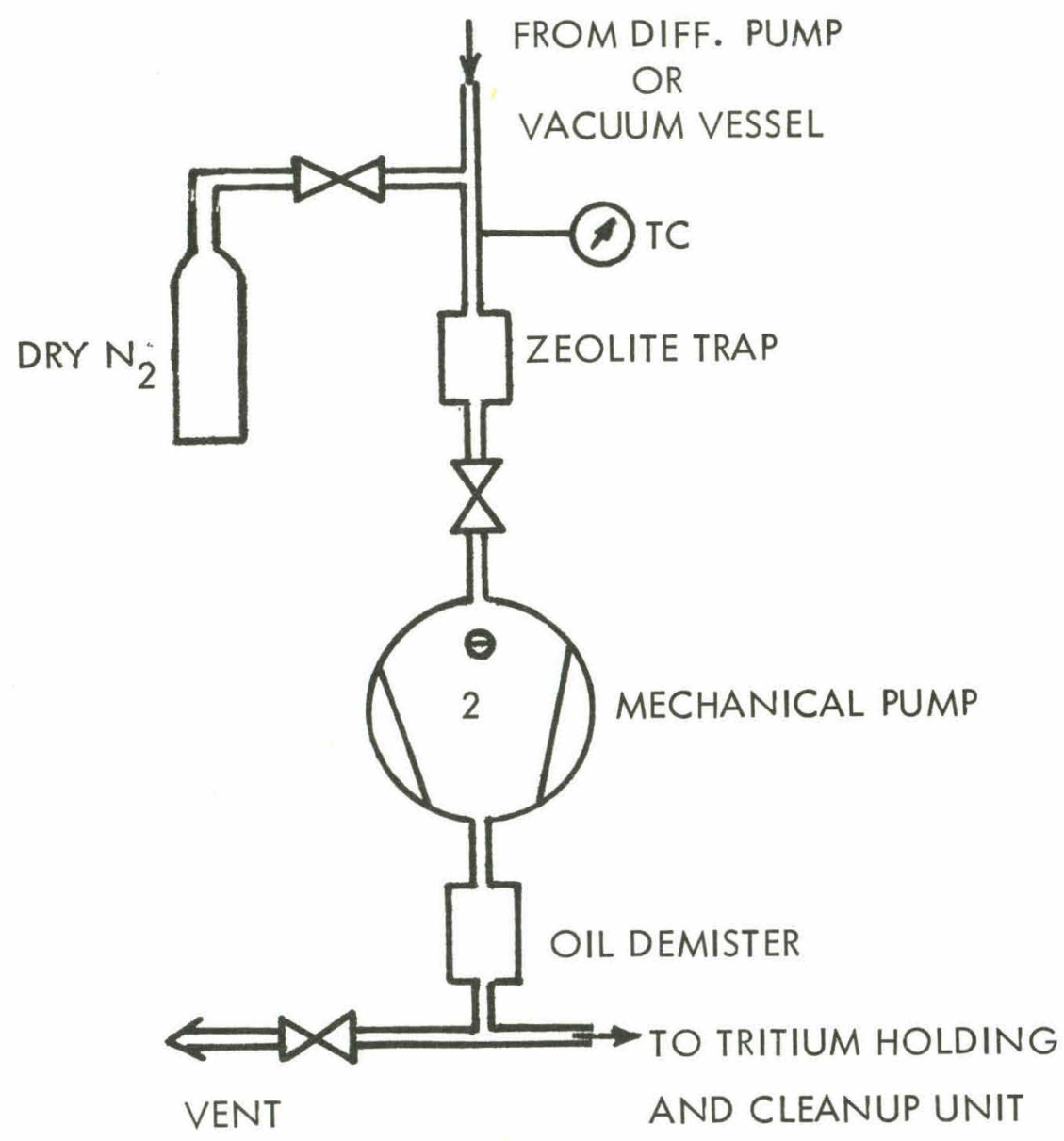

Figure 2.0-2 Schematic of Mechanical Pumping Unit 


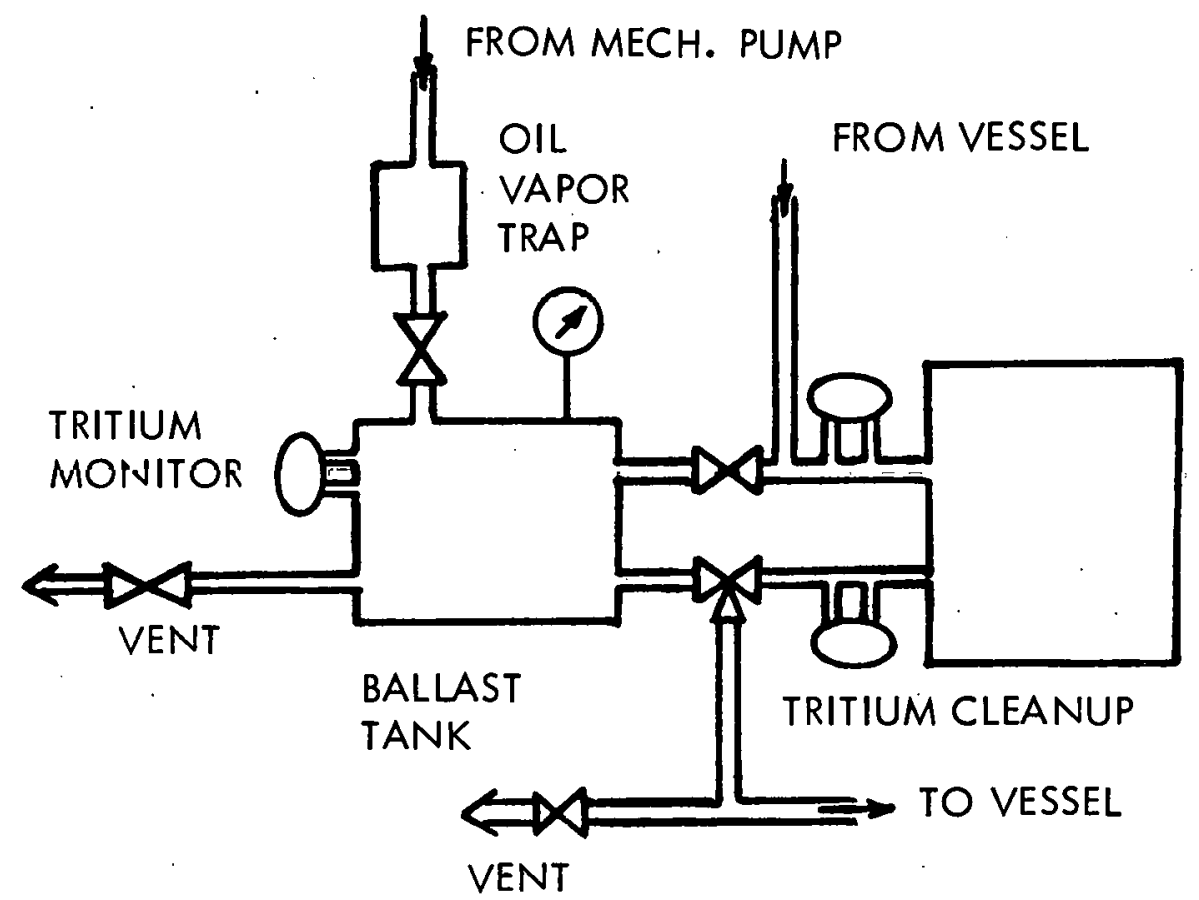

Figure 2.0-3 Schematic of Tritium Holding and Cleanup Unit 


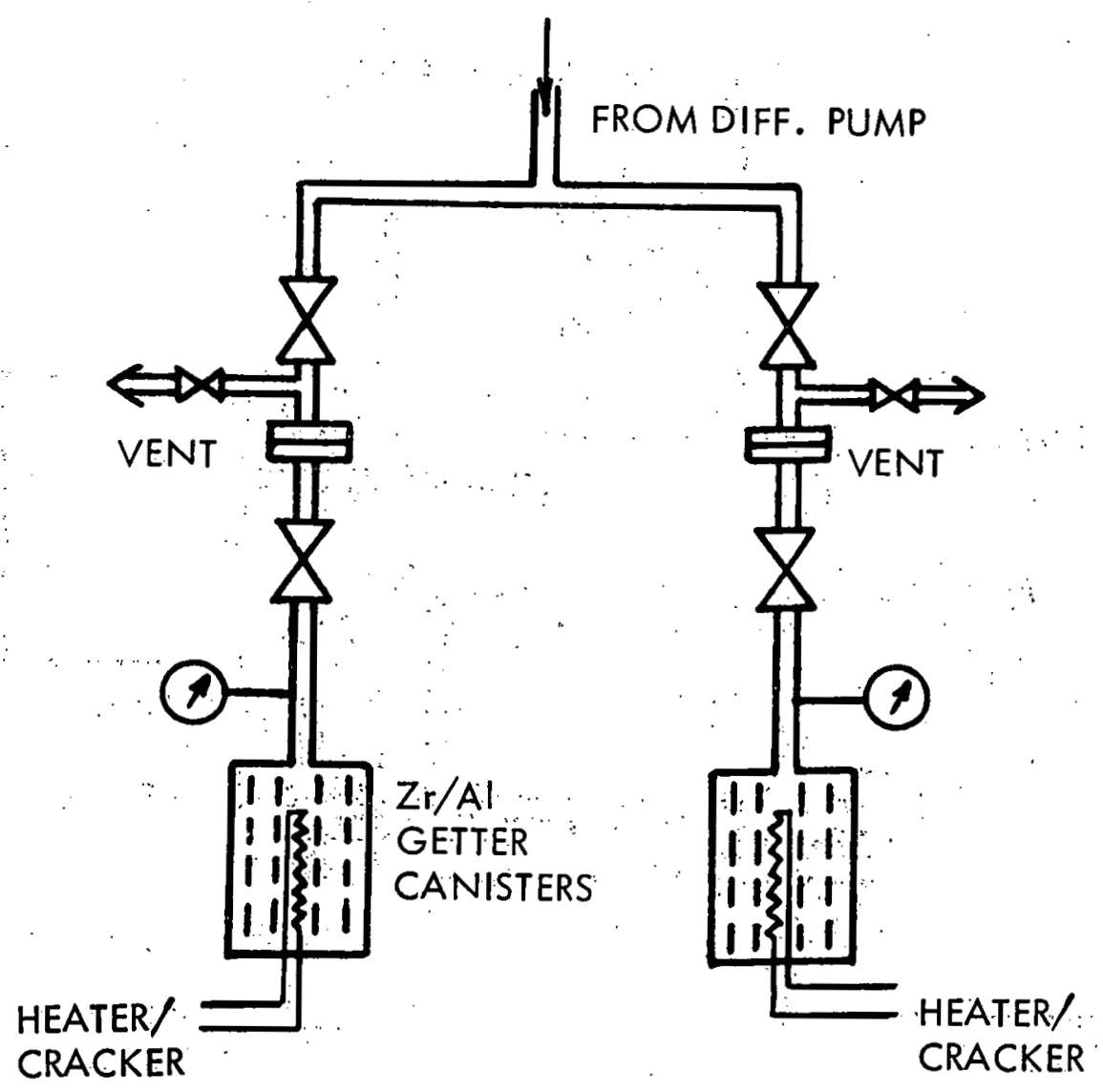

Figure 2:0-4 . Schematic of $\mathrm{Zr} / \mathrm{Al}$ Getter Pumping Unit, 


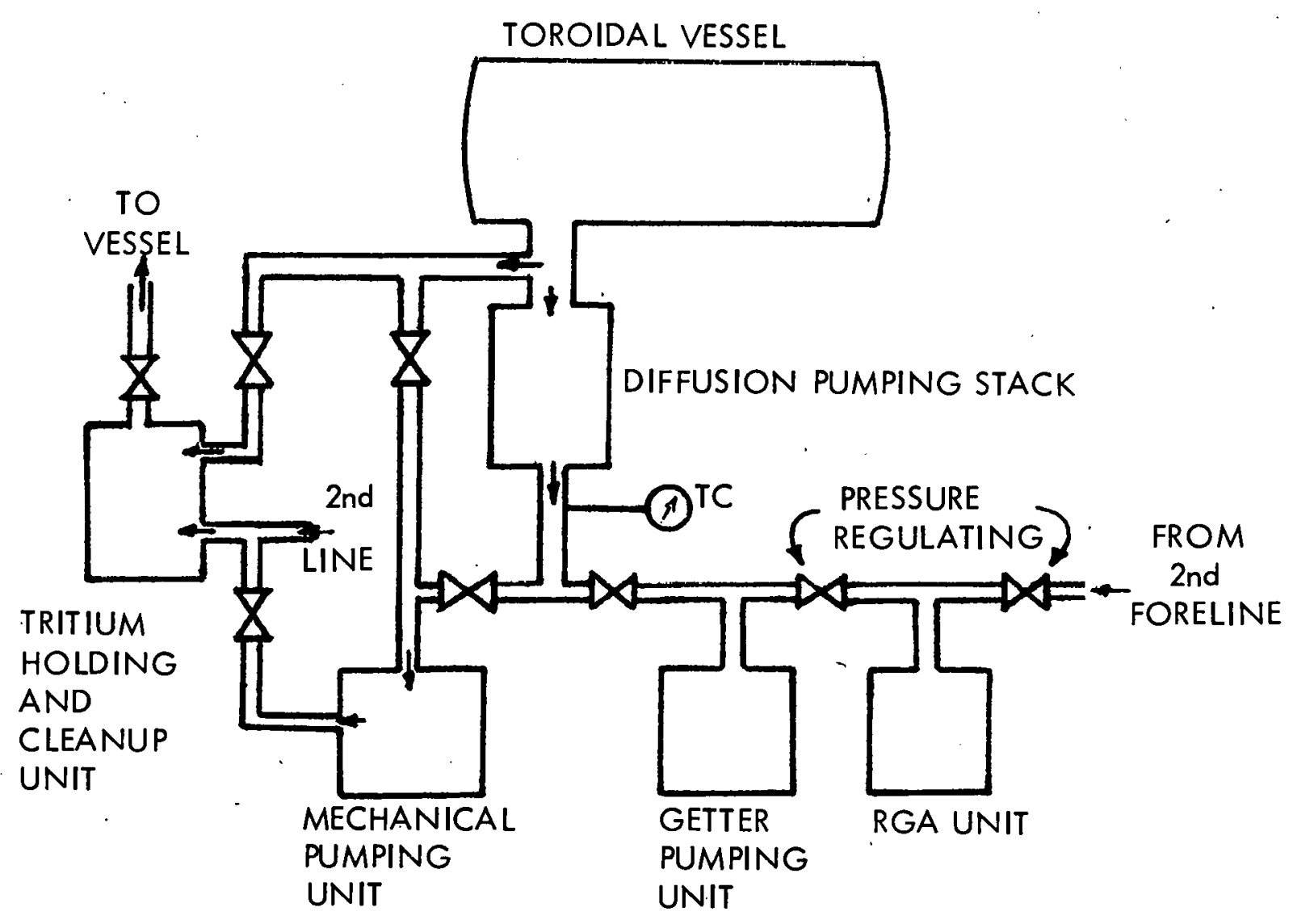

Figure 2.0-5 Block Diagram of Torus Vacuum Pumping System Showing One of the Four High Vacuum Pumping Stacks and Associated Backing System 


\subsection{TFTR VACUUM SYSTEM OPERATION}

\subsection{Base Pressure Considerations}

The torus vacuum system is presently designed to provide a base pressure of $\leq 8 \times 10^{-6} \mathrm{~Pa}$ $\left(6 \times 10^{-8}\right.$ Torr $)$ without in situ bakeout. This pressure was selected on the basis of previous experience at PPPL showing that satisfactory Tokamak plasma performance can be obtained in devices in which the base pressure is below $10^{-5} \mathrm{~Pa}$.

A major source of impurities in plasmas has been gases adsorbed on the surfaces of vacuum vessels or liners which can be "seen" by the plasma. In the pressure range $10^{-5}-10^{-7}$ Pa these surfaces will be covered to saturation with gas molecules in times ranging from a few minutes to a few hours, respectively, after they are cleaned. Moreover, the saturation coverage is essentially independent of pressure. Taking into account the elapsed time between cleaning of the walls by bakeout or discharge cleaning and normal pulsing operation, the coverage on the walls can be anticipated to be complete and independent of the base pressure in this range. Thus a reduction in the base pressure from the presently contemplated $8 \times 10^{-6} \mathrm{~Pa}$ to $1 \times 10^{-7} \mathrm{~Pa}$ is expected to have little effect on the plasma characteristics.

A number of methods of obtaining a low base pressure were considered during the conceptual design of the vacuum system. The application of diffusion pumps using oil as the working fluid is undesirable because the tritium being used in TFTR will result in isotopic exchange and radiation-induced degradation of the oil. Other pumps that were considered include cryopumps, turbopumps, and sputter-ion pumps. Cryopumps were not chosen because of their complexity and because of the thermal loading due to the neutron radiation. Turbopumps were not selected owing to their inherent low compression ratio for hydrogen. In addition, experience at the Westinghouse Research Labs has shown that ultimate pressures for turbopumps are not reliably attained. The periodic maintenance required with these pumps would be relatively complicated after tritium operation. A sputter-ion pump exhausts all gases as does a diffusion pump. However, unlike a diffusion pump, the removed gases are stored in the pump itself, so that when tritium is used it would be stored in the sputter-ion pumps leading to sizable tritium inventory unless the pumps were frequently changed. 
Mercury diffusion pumps were selected as the high vacuum pumps because they are judged to offer the least overall problems in the speration of TFTR. It is also noted that previous experimental devices, as well as PLT at PPPL, have utilized mercury diffusion pumps. The major disadvantages of such pumps are: 1) condensation traps are required to return mercury to the pumps, 2) cold traps operating at $<153 \mathrm{~K}\left(-120^{\circ} \mathrm{C}\right)$ are required to keep mercury vapor out of the torus, 3) the pumping speed for a given diameter pump is less than that for oil charged diffusion pumps, and 4) the largest available mercury pumps are about $60 \mathrm{~cm}$ in digmeter.

Four pumping stacks, each consisting of a mercury diffusion pump, a trap and an isolation valve, are used. Two are flanged directly to the torus and two are located as close as possible to the torus on neutral beam injector arms as shown in Fig. 3.2-1. The total pumping speed provided on the torus, taking into account some restrictions due to the connecting ducts, is approximately $33 \mathrm{~m} / \mathrm{s}$ for $\mathrm{H}_{2}$. The total influx of gas, together with this speed, determines the base pressure. One can assume a value of $10^{-7} \mathrm{~Pa} \mathrm{~m} / \mathrm{s} \mathrm{m}^{2}$ for the specific outgassing rate of the surfaces exposed to the vacuum. This rate has been obtained by many workers for stainless steel in unbaked systems after several hours of pumping. Since the dominant gas evolved is hydrogen, one can expect the base pressure in TFTR, having $10^{3} \mathrm{~m}^{2}$ of exposed surface area, to be $3 \times 10^{-6} \mathrm{~Pa}$. It should be pointed out that this estimate is only accurate to within an order of magnitude because the actual outgassing rates are not yet known.

\section{$3.2 \quad$ Pumpout and Fill Times}

The desired base pressure together with the expected outgassing rate determine the necessary pumping speed. The volume of the system divided by this pumping speed gives a time constant or e-folding time for pumpout of a few seconds depending upon the particular gas, e.g., the time constant for $T_{2}$ is $\sim 4 \mathrm{~s}$. This time is considerably shorter than the time between pulses (300 sec) so that the base pressure should be easily re-established in $\sim 30 \mathrm{~s}$,well before a succeeding pulse. Another time constant of interest is that for the filling equilibration within the torus of a gas admitted at one Inration on the torus. For $T_{2}$, this time constant for filling is $\sim 0.13$ s. 


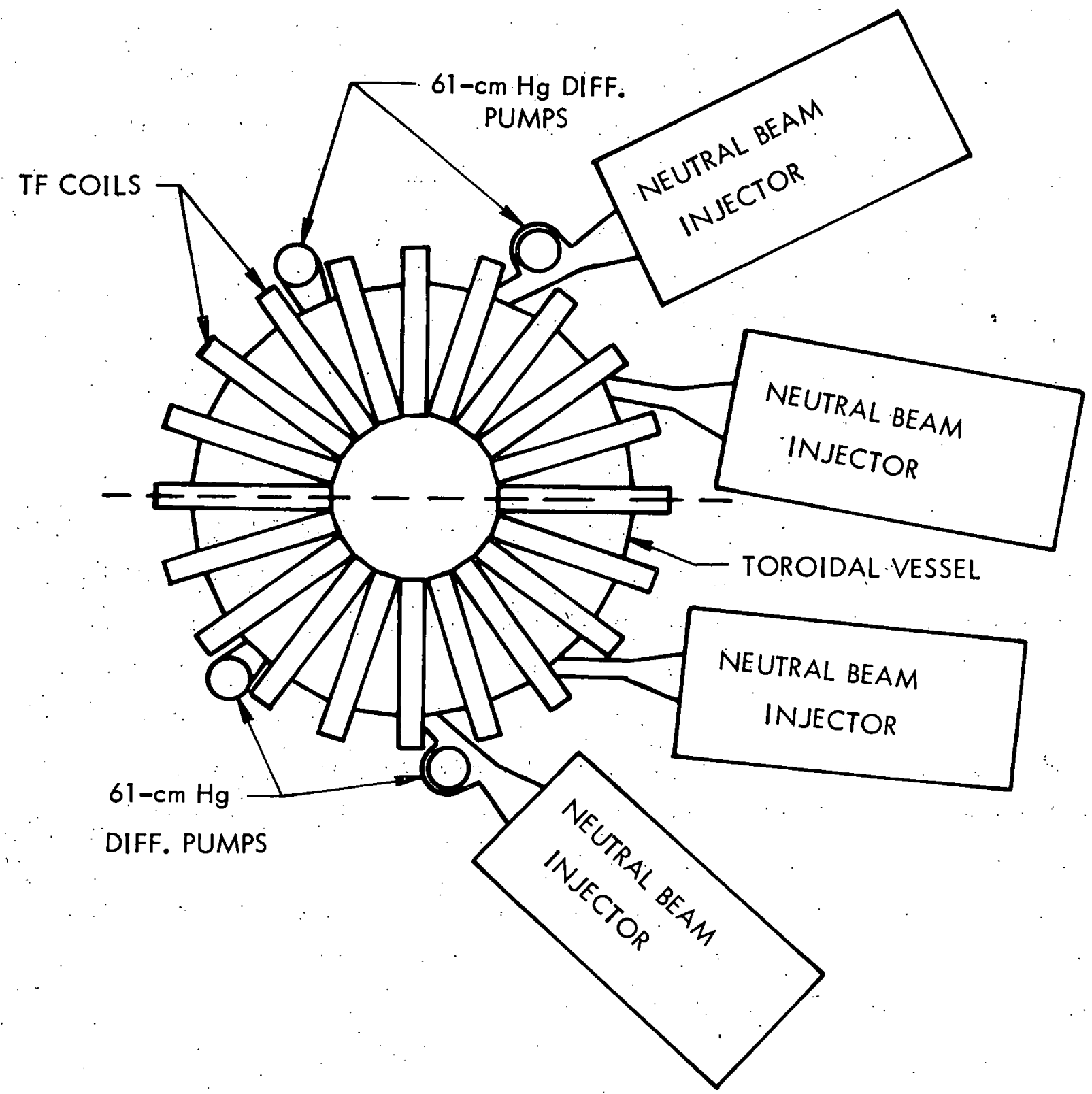

Figure 3.2-1 The Location of the Diffusion Pumps on the TFTR Vacuum Vessel 


\subsection{Monitoring the Forelines Using Residual Gas Analyzers}

The design of the vacuum system includes the use of residual gas analyzers (RGA's) to monitor the foreline partial pressures in the main torus and neutral beam injectors. The principal function of the RGA's will be to determine the level of tritium and tritiumbearing gaseous species. A second use of the RGA's is anticipated to be that of assisting in leak detection. A schematic of the vacuum system for an RGA is shown in Fig. 3.3-1.

The question has been asked as to the ability of an RGA to "see" the tritium in a gas mixture also containing hydrogen and deuterium gases. Although the gas composition will not be as simple as that used in the sample spectra presented in Section 3.3.2, it should be evident that the technique is amply demonstrated by these sample spectra and that the use of high speed computers will enable deduction and display of the gas species, e.g., tritium essentially in real time.

\subsubsection{Assumptions}

The calculated spectra presented in the next section are based on the following conditions and assumptions, which are judged to be sufficiently close to the anticipated actual cases to be meaningful:

- A commercial RGA, for example, of the quadrupole type, having a resolving power of approximately $50(M / \triangle M=50)$, would be used;

- The major gas species would be hydrogen or a combination of hydrogen isotopes;

- The impurity gases would be methane, water, and carbon monoxide, and each would comprise $5 \%$ of the total pressure;

- Mixing via isotopic exchange would be complete, i.e., it is assumed that any and all hydrogen isotopes would form deuterated and tritiated gaseous compounds such as water and methane, and that the percentages of such compounds would be that which would be obtained at steady state; 


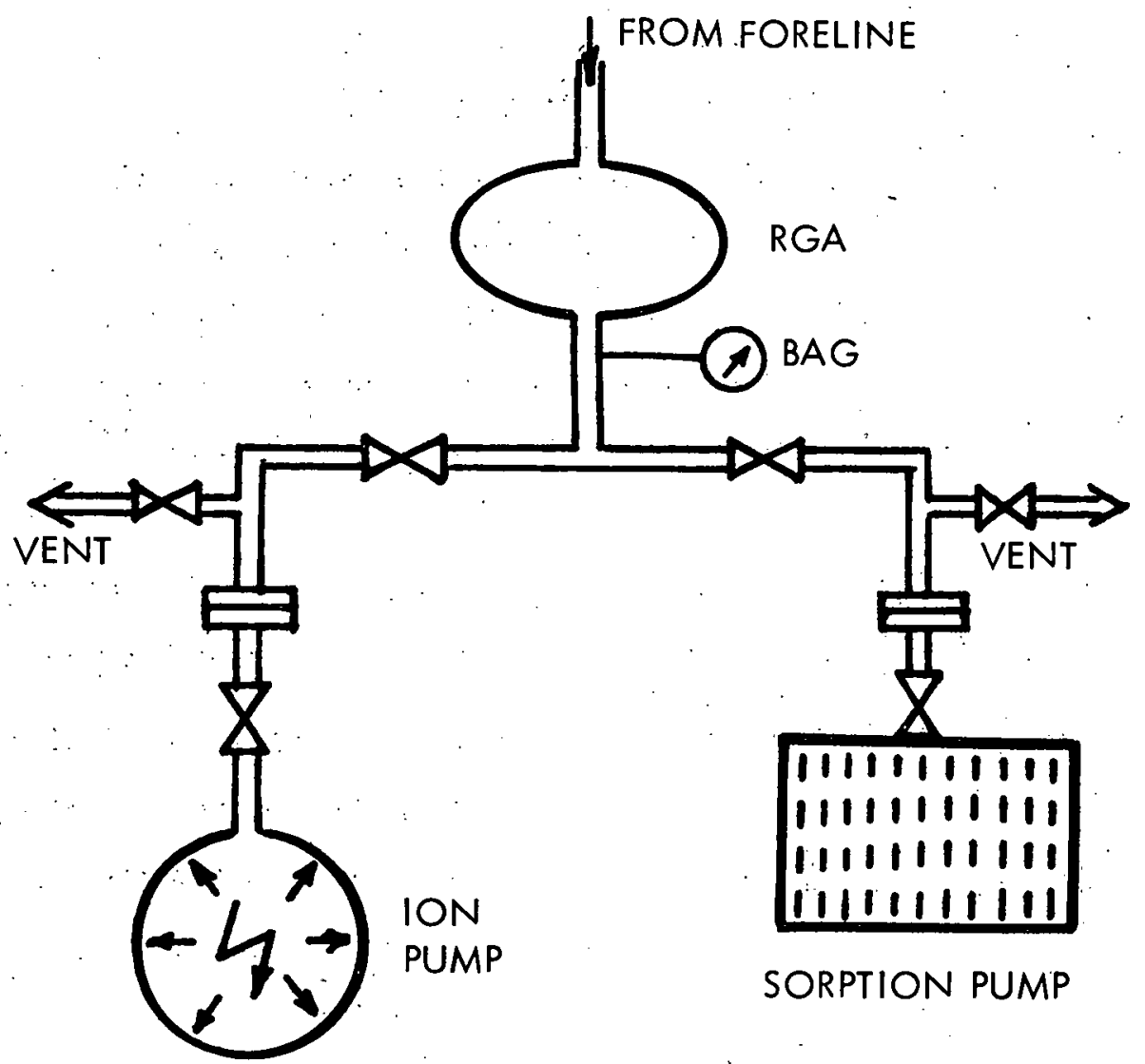

Figure 3.3-1 RGA Vacuum System 
- The sensitivities for the various gas species and the cracking patterns would be typical of those observed with RGA's;

- The RGA sensitivity and cracking pattern for a given gas would be independent of the particular hydrogen isotope(s) involved, e.g., the sensitivities and cracking patterns for $\mathrm{CH}_{x} \mathrm{D}_{y} \mathrm{~T}_{z}$ and $\mathrm{CH}_{4}$ are taken to be equal.

Three operating conditions of TFTR are assumed corresponding to the anticipated chronological operation: first, operations with an $\mathrm{H}_{2}$ plasma; second, operation with an $\mathrm{H}_{2}$ plasma and neutral beam injection of deuterium; and, third, operation with a tritium plasma and neutral beam injection of deuterium.

A comparison of the spectra derived for these three operational conditions will show the relctive ease of unravelling the spectra to determine the true partial pressures of the gases and, in particular rof the hydrogen isotopes. While one does not know at this time the actual composition of gases to be found in the fore racuum, an estimate of the composition can be made on the basis of previous general experience. Admittedly there will be, in addition to the gases assumed for the spectra presented here, other gases including hydrocarbons of greater complexity than methane. Moreover, if the $\mathrm{Zr} / \mathrm{Al}$ getters perform as expected, the partial pressures of the hydrogen isotopes will be very markedly reduced relative to the impurities such as water vapor, carbon monoxide, and methane assumed in the sample spectra given here. The assumed partial pressure of methane is high relative to our experience, but is so taken to not be overly optimistic and to allow for the possibility that it may be produced by the plasma operation.

As with many or most of the other systems and sub-systems, those involved will prove out . the techniques employed and learn a great deal of detail regarding eventual operation with tritium and deuterium from the earlier experiments. 


\subsubsection{Expected RGA Results}

Figure 3.3-2 shows the anticipated peak heights as a function of the mass to charge ratio, We, of the analyzed ions for a gas consisting of $85 \% \mathrm{H}_{2}$ and $5 \%$ each of $\mathrm{CH}_{4}, \mathrm{H}_{2} \mathrm{O}$, and $\mathrm{CO}$. The only features to note are the contributions to certain $\mathrm{Me}$ peaks by more than one gas. For example, the $\mathrm{Me}=16$ peak includes a main contribution of $\mathrm{CH}_{4}^{+}$ and minor contributions of $0^{+}$from $\mathrm{H}_{2} \mathrm{O}$ and to a lesser extent from $\mathrm{CO}$. See Table 3.3-1.

Figure 3.3-3 shows the spectrum one would obtain for a hydrogen plasma with neutral beam injection of deuterium assuming the ratio of hydrogen to deuterium to be $60: 25$ with these isotopes comprising $85 \%$ of the total gas. Again carbon monoxide, methane, and water vapor are assumed to comprise $5 \%$ each. As stated earlier, complete mixing is assumed, thus yielding deuterated methane and water vapor. Comparison with Fig. 3.3-2 shows the marked differences in the spectra and shows the presence of deuterium, especially from the $M / e=1$ through $M / e=4$ peaks. It is also worth noting that the contribution to the $\mathrm{Me}=2$. peak is overwhelmingly $\mathrm{H}_{2}^{+}$, while $\mathrm{D}^{+}$from $\mathrm{HD}$ and $\mathrm{D}_{2}$ is so small as to be essentially negligible.

The spectrum shown in Fig. 3.3-4. is obtained for the conditions of a tritium plasma with one deuterium atom injected for every two tritium atoms and assuming impurities of $\mathrm{H}_{2}$ $(8 \%), \mathrm{He}^{3}(2 \%)$, and methane, water vapor, and carbon monoxide (5\% each), Again there are several features of the spectrum which immediately signal the presence of the heavier hydrogen isotopes, despite the contributions to certain $W$ e peaks from the. 15 combinations of deuterated and tritiated methane and 6 such combinations for water. vapor.

The output of the RGA would be fed to an on-line computer which would be programmed to derive the partial pressures of each gas species and the total tritium 


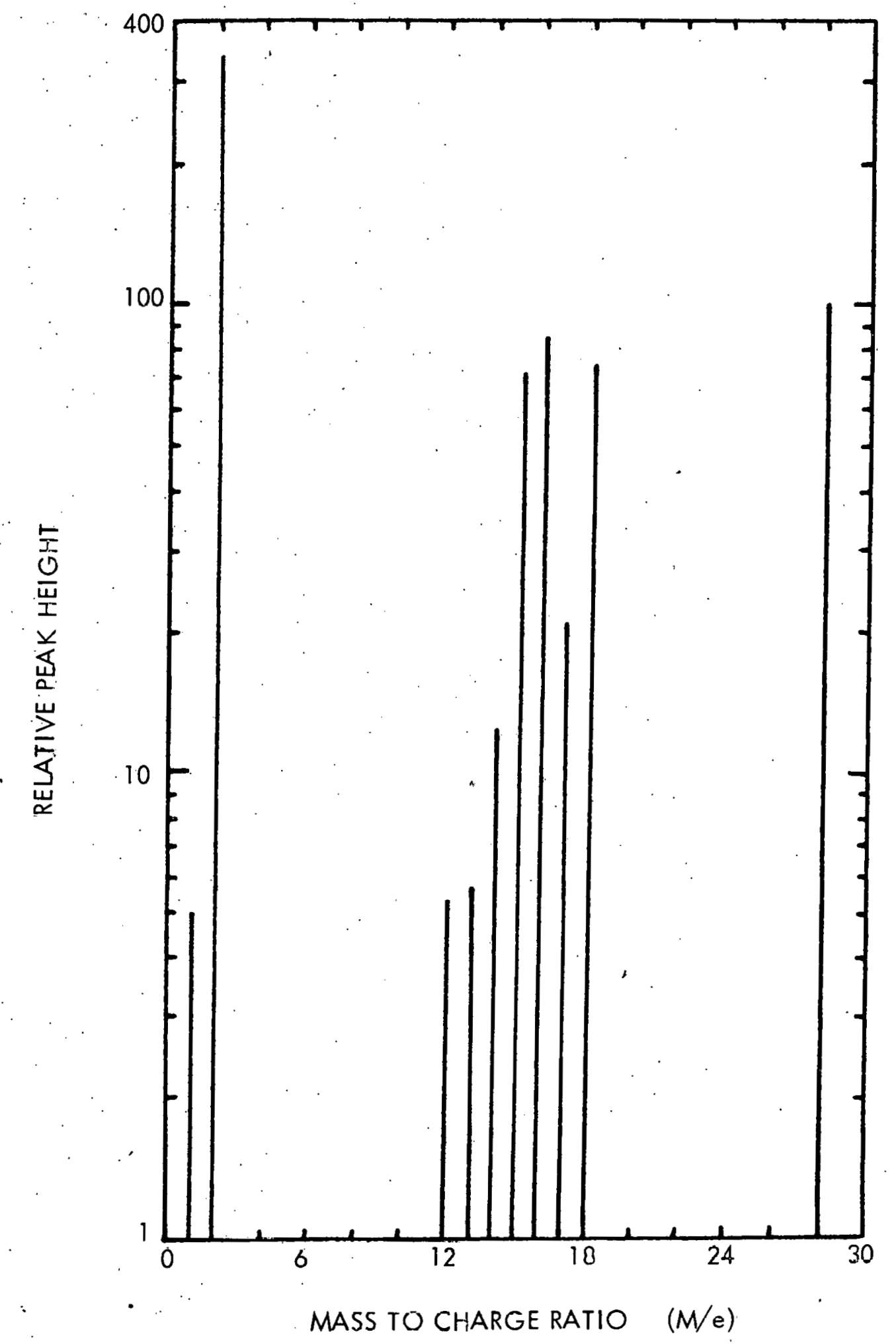

Figure 3.3-2 RGA-derived $\mathrm{We}$ Spectra for Operations With an $\mathrm{H}_{2}$ Plasma 


\begin{tabular}{|l|l|l|l|l|l|l|l|l|l|l|l|l|l|}
\hline $\mathrm{Gas}^{\mathrm{Ne}}$ & 1 & 2 & 4 & 12 & 13 & 14 & 15 & 16 & 17 & 18 & 28 & 29 & 30 \\
\hline $\mathrm{H}_{2}$ & 1.49 & 100 & & & & & & & & & & & \\
\hline $\mathrm{He}$ & & 1.38 & 10 & & & & & & & & & & \\
\hline $\mathrm{CH}_{4}$ & 0.007 & 0.46 & & 2.66 & 7.23 & 14.81 & 88.81 & 100 & 1.11 & & & & \\
\hline $\mathrm{H}_{2} \mathrm{O}$ & & 0.1 & & & & & & 3.07 & 27 & 100 & & & \\
\hline $\mathrm{CO}$ & & & & 3.19 & & 0.38 & & 1.63 & & & 100 & 1.03 & 0.19 \\
\hline
\end{tabular}

Estimated Sensitivities (Relative)

$\begin{array}{ll}\mathrm{H}_{2}, \mathrm{D}_{2}, \mathrm{~T}_{2} & 20 \\ \mathrm{He} & 10 \\ \text { Methane }\left(\mathrm{CH}_{x} \mathrm{D}_{y} T_{z}\right) & 80 \\ \text { Water }\left(\mathrm{H}_{x} \mathrm{D}_{y} T_{z} \mathrm{O}\right) & 75 \\ \mathrm{CO} & 100\end{array}$

Table 3.3-1 Tabulation of the relative peak neights shown in Figure 2.3-1. 


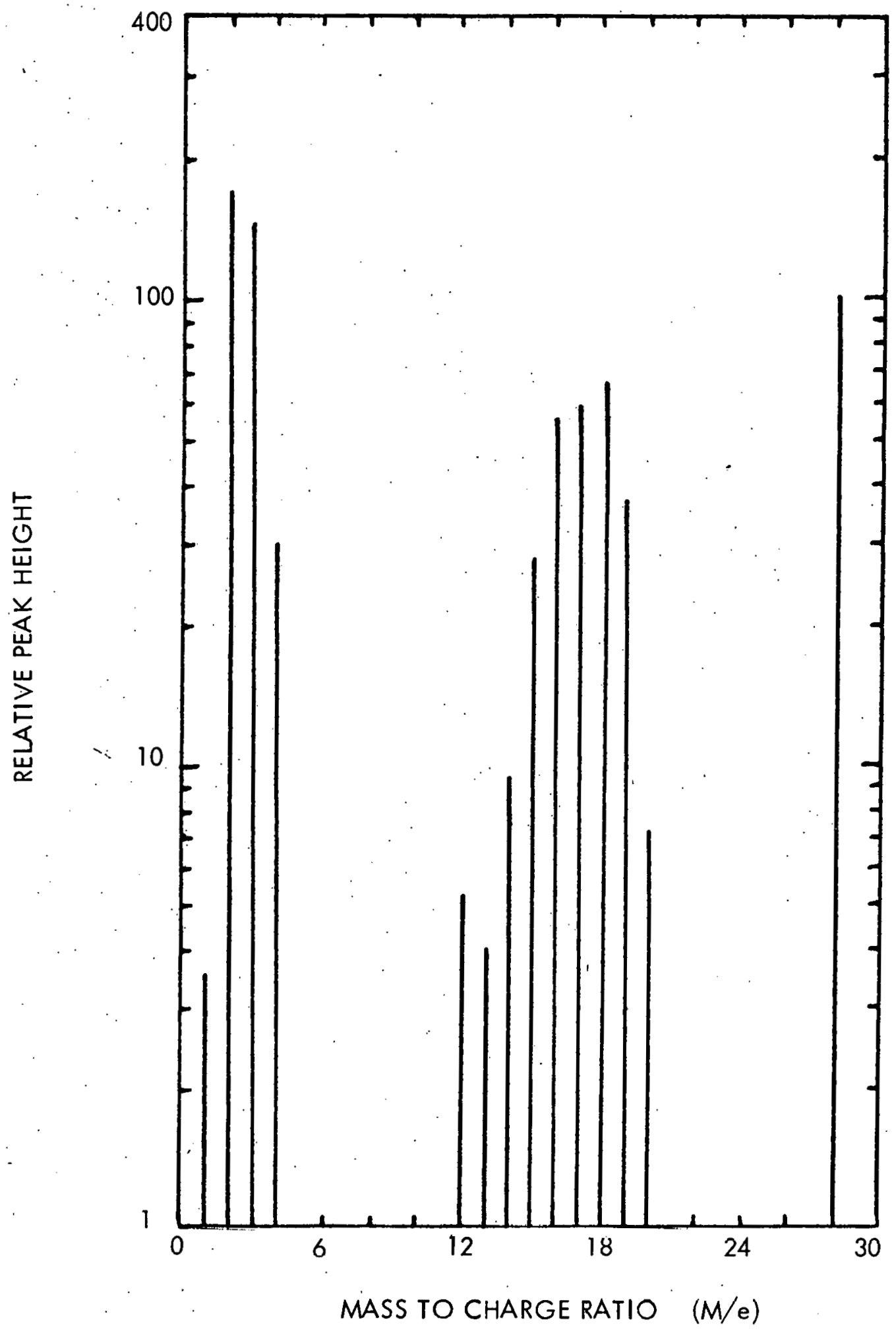

Figure 3.3-3 RGA-derived $M /$ e Spectra for Operations with an $\mathrm{H}_{2}$ Plasma and Neutral Beam Injection of Deuterium 


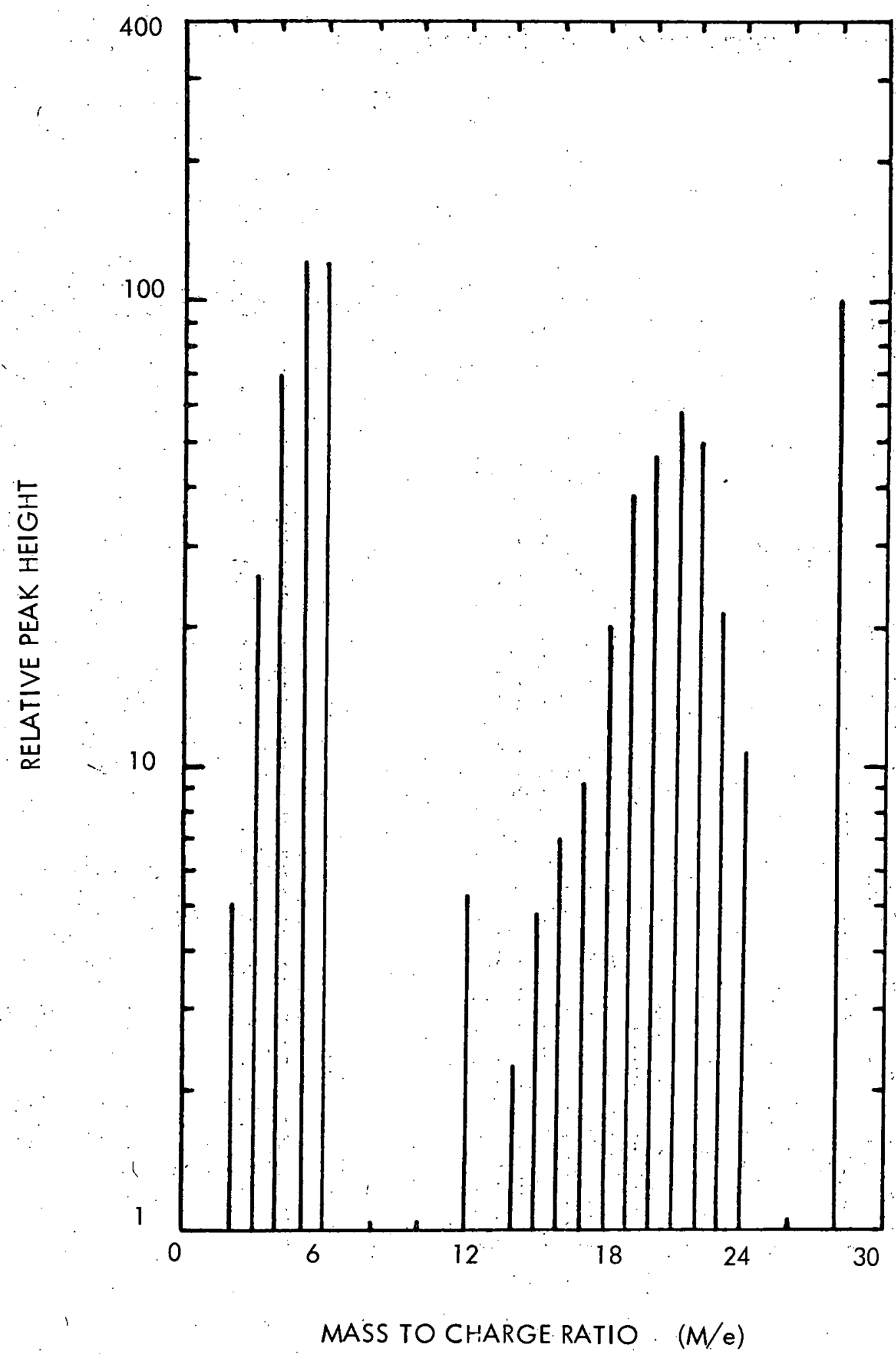

Figure 3.3-4 RGA-derived M/e Spectra for Operations with a Tritium Plasma and Neutral Beam Injection of Deuierium 
present by solving a set of simple algebraic simultaneous equations representing the relative sensitivities and cracking patterns for each expected species. Admittedly the spectra will be somewhat more complicated as a result of incomplete mixing of $H, D$, and $T$ atoms and minor contributions from some heavier hydrocarbons. Nevertheless, the problem is surely tractable and provides the monitoring of tritium in the foreline necessary to ensure the quality of the discharge from the mechanical vacuum pumps. In addition, the RGA's will monitor the performance of the getters.

The typical RGA has a dynamic range of approximately $10^{6}$, so that the quantitative presence of a given species relative to the total quantity of gas is approximately $10^{6}$. This means that for a fore pressure of $1 \mathrm{~Pa}$, one can expect to detect $\mathrm{T}_{2}$ at a partial pressure of $10^{-6} \mathrm{~Pa}$ or a density of $10^{8} \mathrm{~cm}^{-3}$. For a foreline volume of $0.1 \mathrm{~m}^{3}$, this corresponds to $10^{13}$ molecules or $1 \mu \mathrm{Ci}$ of $\mathrm{T}_{2}$.

Finally, it can be anticipated that the RGA's will prove vital in diagnosing any peculairities or malfunctions of the pumping systems by indication of an unusual gas species, e. g., argon which would signal a leak to the atmosphere. A useful scheme for leak checking might be to operate the ion source of the RGA so that multiple ions are produced in unusually high abundances, and using argon as the tracer gas, set the RGA to read the $\mathrm{Ar}^{++}$peak at $M / e=13-1 / 3$ where with reasonable resolution other gas species would not contribute to the signal. 


\subsection{VACUUM SEALS}

\section{1 Basic Considerations}

The purpose of Section 4 is to discuss the requirements for the seals on the TFTR vacuum system and to present the reasons for selecting flat copper washer seal (conflat ${ }^{(4)}$ seal) for general use on all demountable flanges and joints. This selection does not preclude the use, in particular situations, of welded joints or gold wire seals. The welded joints are designed to be cut and rewelded on infrequent occasions. Such joints will be used in joining the two halves of the toroidal vacuum vessel as well as where space limitations prohibit the demounting of the gasket-flange type of joint.

In order to maintain impurity levels in TFTR at acceptable levels, it was concluded that the specific outgassing rate of impurities (non-hydrogen species) should not exceed $10^{-9}$ $\mathrm{Pa} \mathrm{m} / \mathrm{s} \mathrm{m}^{2}$. Attainment of such outgassing rates are typically ensured by baking the entire vacuum system to $675-725 \mathrm{~K}$. In the case of the TFTR vacuum system a high temperature bakeout in situ may not be necessary but it is still imperative that ultrahigh vacuum techniques be employed. Thus, while the bakeout feature of the design and construction of such seals automatically provides the required UHV integrity, it will be necessary to pre-bake subassemblies including pre-assembled seals to guarantee a specific outgassing rate of impurities $\lesssim 10^{-9} \mathrm{~Pa} \mathrm{~m} / \mathrm{s} \mathrm{m}^{2}$. The very effective method of discharge clearing will be used to remove surface contamination that takes place during assembly of the system and subsequently when the system is opened for changes or repairs. : Since subassemblies will be pre-baked, seals that are capable of withstanding high temperature cycling are mandatory. Another argument for such seals is that operations of the device, e.g., discharge cleaning, could lead to large temperature excursions of parts of the vacuum system and that seals which have been proven reliable under thermal cycling stand the best chance of surviving this unusual treatment. Finally, the issue of in situ bakeout of the entire system is still not entirely settled 
and is under active investigation. For these reasons, our choice of seals is narrowed to those that can be categorized as bakeable, ultrahigh vacuum seals. A discussion of in situ bakeout is presented in Section 6.

For the purposes of the present discussion a plausible set of seals is listed in Table 4.1-1. The diagnostic ports will have openings ranging from $2.5 \mathrm{~cm}$ dia. to $25 \mathrm{~cm}$ dia.; a $10 \mathrm{~cm}$ dia. port was chosen as a representative size. It is visualized that many of the large ports will accomodate a number of diagnostics with each requiring individual seals. As listed, there would be a total of over 400 individual seals from which it is immediately evident that a very high degree of reliability in the seal performance is mandatory.

\subsection{Criteria for the Selection of Vacuum System Seals}

The main criteria for the selection of the vacuum system seals are listed below. Only seals which are categorized ás ultrahigh vacuum seals as defined by reference to the AVS standard on seals ${ }^{(5)}$ which specifies the leak rate, sealing life, bakeability, the ability to. leak detect, and so forth, has been considered.

- The seals must not be a source of impurities either by outgassing or permeation.

- The seals must not permit permeation of tritium out of the vacuum vessel.

- The seals must be capable of withstanding the neutron fluxes and gamma-ray doses anticipated for the TFTR. 


\begin{tabular}{|c|c|c|c|c|c|c|}
\hline ITEM & $\begin{array}{l}\text { Typical Seal } \\
\text { Length on Item }\end{array}$ & $\begin{array}{l}\text { Number of } \\
\text { per ltem }\end{array}$ & & $\begin{array}{l}\text { Number of Items } \\
\text { per machine }\end{array}$ & $\begin{array}{l}\text { Number of Seals } \\
\text { per-item machine }\end{array}$ & $\begin{array}{l}\text { Total Seal Length } \\
\text { per-item machine }\end{array}$ \\
\hline $\begin{array}{l}\text { 61-cm dia. } \mathrm{Hg} \\
\text { Diff. Pump }\end{array}$ & $\begin{array}{l}\pi \times 0.61 \mathrm{~m} \\
\approx 2 . \mathrm{m}\end{array}$ & 3 & . & 4 & 12 & $24 \mathrm{~m}$ \\
\hline $\begin{array}{l}\text { Neutral Beam } \\
\text { Injector Lines }\end{array}$ & $\begin{array}{l}(1.0 \mathrm{~m} \times 1.8 \mathrm{~m}) \times 2 \\
=5.6 \mathrm{~m}\end{array}$ & 3 & & 6 & $\begin{array}{l}\therefore \quad: \\
\therefore \quad 18\end{array}$ & $100 \mathrm{~m}$ \\
\hline Large Ports & $\begin{array}{l}(1.0 \times 1.8 \mathrm{~m}) \times 2 \\
=5.6 \mathrm{~m}\end{array}$ & $\because$ & & 12 & 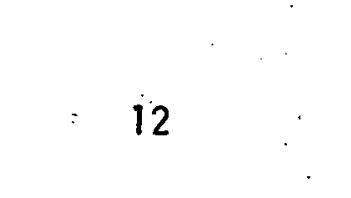 & $67 \mathrm{~m}$ \\
\hline Diagnostic Ports & $\begin{array}{l}\pi \times 0.1 \mathrm{~m} \\
\approx 0.31 \mathrm{~m} \\
\therefore\end{array}$ & 1.5 & & 250 & 375 & $116 \mathrm{~m}$ \\
\hline TOTALS & $\because "$ & & & & 417 & $307 \mathrm{~m}$ \\
\hline
\end{tabular}

Table 4.1-1 PORT SEALS FOR TFTR 
- The seals must be adaptable to remote handling.

- The seals should be of a proven design and be in a wide range of sizes.

- The seals should have the lowest initial cost as well as the lowest usage cost consistent with meeting technical objections.

\subsection{Comparison of Metal Gasketed Seals}

When consideration is given to the above criteria, the choice of seals narrows to two, the gold wire corner seal $(6)$ and the copper Conflat seal. $(7,8)$ Since the latter seal is in general usage within the vacuum industry and also has an inherent ability to be adapted for remote handling that seal was chosen. The oxygen-free high-conductivity (OFHC) copper gasket for the Conflat seal is $0.203 \mathrm{~cm}\left(0.080^{\prime \prime}\right)$ thick and is in the form of a washer having an annular width of $0.635 \mathrm{~cm}\left(0.25^{\prime \prime}\right)$ or more depending on the flange size. These gaskets are self-supporting and can be fitted to the flange directly without complication. The dimensional tolerance on the concentricity of the conical sealing ridges of the sexless flanges is $\pm 0.013 \mathrm{~cm}\left( \pm 0.005^{\prime \prime}\right)$ which is compatible with remote handling. Further support for our selection of the Conflat seal design lies in the fact that such commercially available seals are virtually universally accepted and successfully used. In addition, relatively minor design details, including rotatable flanges and gasket retention for vertical flanges, are available and proven in the field.

Of course the presently available Conflat designs will be modified with pilot pins, lifting lugs, or other features to accomplish the remote handling operations. Success with circular seals larger than $25 \mathrm{~cm}$ dia. and with $0.56 \mathrm{~m} \times 0.13 \mathrm{~m}\left(22^{\prime \prime} \times 5^{\prime \prime}\right)$ rectangular seals incorporated in a commercial analytical instrument is reported. (9) The original designer of these flanges, W. R. Wheeler, believes that a $61 \mathrm{~cm}$ dia. Conflat can be made and, in 
fact, he has suggested that the Conflat design is more reliable and preferable to the Wheeler copper wire seal (8) for the TFTR application. He gave economics and marketability as the reasons for Conflat seals not being available commercially in larger circular sizes or in non-circular geometries. These reasons apply to both the Conflat and gold wire seals. He did caution that OFHC copper sheet, having high surface quality, could be difficult to obtain in widths greater than $61 \mathrm{~cm}$.

The initial cost of Conflat seals might be less than the cost of gold wire corner seals: This judgement is based on the somewhat less stringent manufacturing tolerances needed for the Conflat.: Both types of seals need rigid flanges and require about the same clamp-ing force as is shown in the load-deflection curves, Fig. 4.3-1. : The usage cost of the two different seals, as reflected in the cost of the gaskets, is judged comparable if the gold can be reclaimed at approximately $80 \%$ of its original cost." (The reclaim value of neutron activated gold could change this up or down and has not been determined at this time.) In any event, neglecting the cost of carrying a differential inventory of 20 or 30 thousand dollars in gold, the: usage cost of either type seal over a five year period should not exceed 10 percent of the initial cost of the flange assemblies.

\subsection{ZIRCONIUM - ALUMINUM GETTERS}

\subsection{Getter Characteristics}

The design of the vacuum system for TFTR is predicated on bonding hydrogen isotopes especially tritium, chemically with a getter. The gettering units which have been selected for this purpose contain cartridges of a zirconium - $(16 \%)$ aluminum alloy. The supplier of the $\mathrm{Zr} / \mathrm{Al}$-type of getter, $(\mathrm{SAES})^{(10)}$, indicates that good absorption characteristics with 


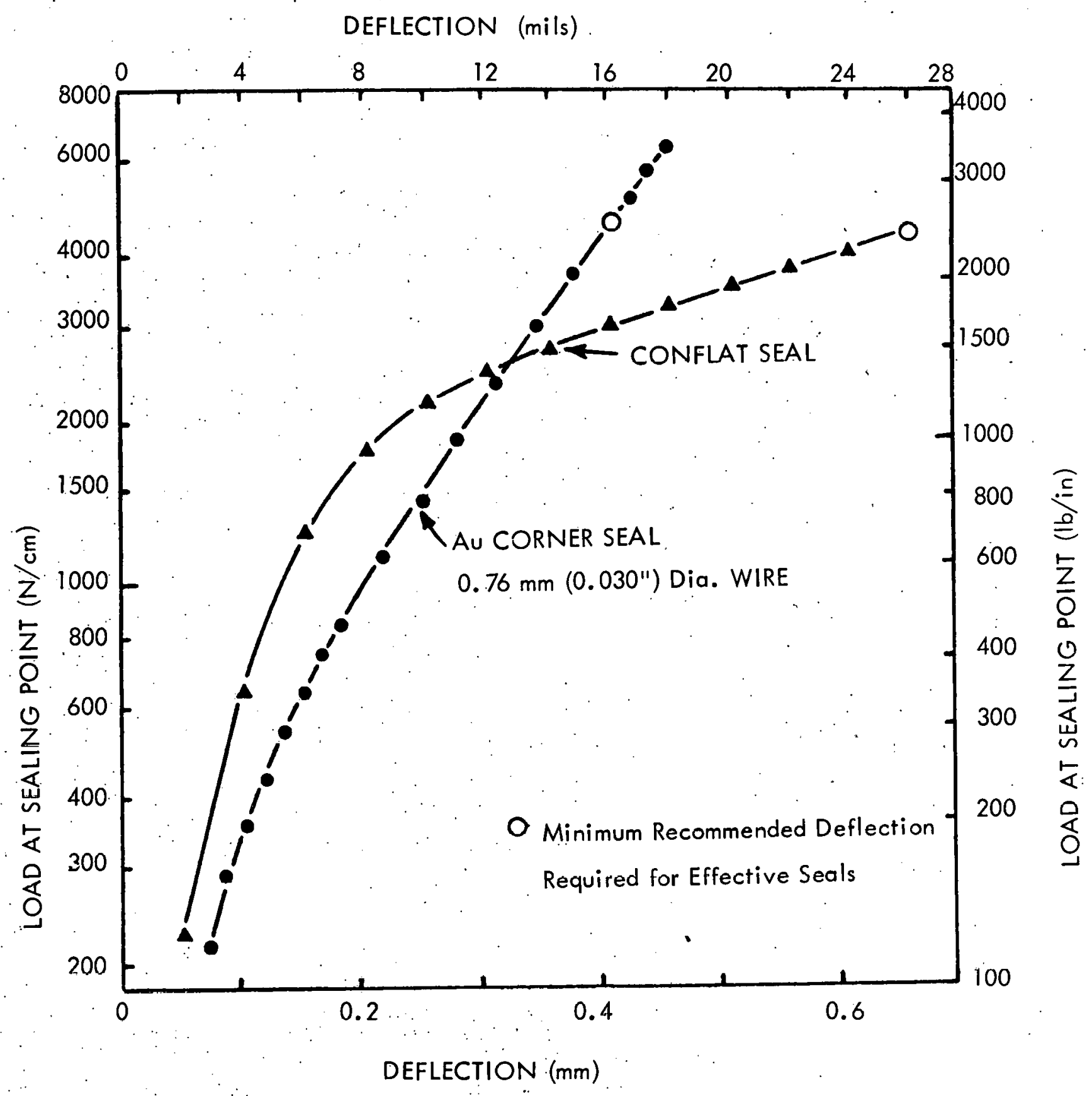

Figure 4.3-1 Load-deflection Data for Seals Used at $\cong$ Research Laboratories 
this alloy are available but that there are indications that contaminants may impose limits. The concept of regeneration rather than single usage has been introduced when a system of $\mathrm{Zr} / \mathrm{Al}$ getters are used thus offering a cost savings. The $\mathrm{Zr} / \mathrm{Al}$ getter supplier indicates that in excess of 20 regenerations can be conducted before degradation effects become significant in conventional gas purification/vacuum operations, due to irreversible chemical reaction of active gases with the zirconium. It was recently reported that, for systems that are lean with regard to the irreversible compound formers, excellent performance is obtained even after 50 - 60 regenerations. No information is available on performance with radioactive tritium or with tritiated hydrocarbons. Tests are required to establish the limit of repeated regenerations and recycling of getter cartridges and to supply a basis for real istic operating cost estimates. An initial study has been undertaken to obtain performance characteristics of these devices under the operating conditions which are expected in TFTR.

\subsection{Status of the Initial Zr/Al Getter Study}

Working with small getter pumps (small with respect to those contemplated for TFTR) we have obtained results consistent with SAES claims. These pumps have an active area for pumping which is about $1 / 65$ that for the $C-500$ cartridges proposed for TFTR. Photographs of a SAES getter are shown in Figure 5.2-1.

Using "pure" hydrogen and operating the getters at ambient temperatures (300 K) we have exposed the getters to hydrogen gas pulses of approximately $0.1 \mathrm{~Pa} \mathrm{~m}^{3}$ with gas pulses at either every minute or every five minutes. Following gettering of a quantity in excess of the rated capacity, the getters have been reactivated by heating to $1148 \mathrm{~K}$. We have not attempted to determine how many times the getters can be reactivated without deterioration in either capacity or speed, but two getters have been cycled 20 times each and show no deterioration.

To study the pumping of methane, we have used a tungsten filament having an area of $1: 8 \mathrm{~cm}^{2}$ and operated at $22500 \mathrm{~K}$ to "crack" the gas. The cracking process proceeds 

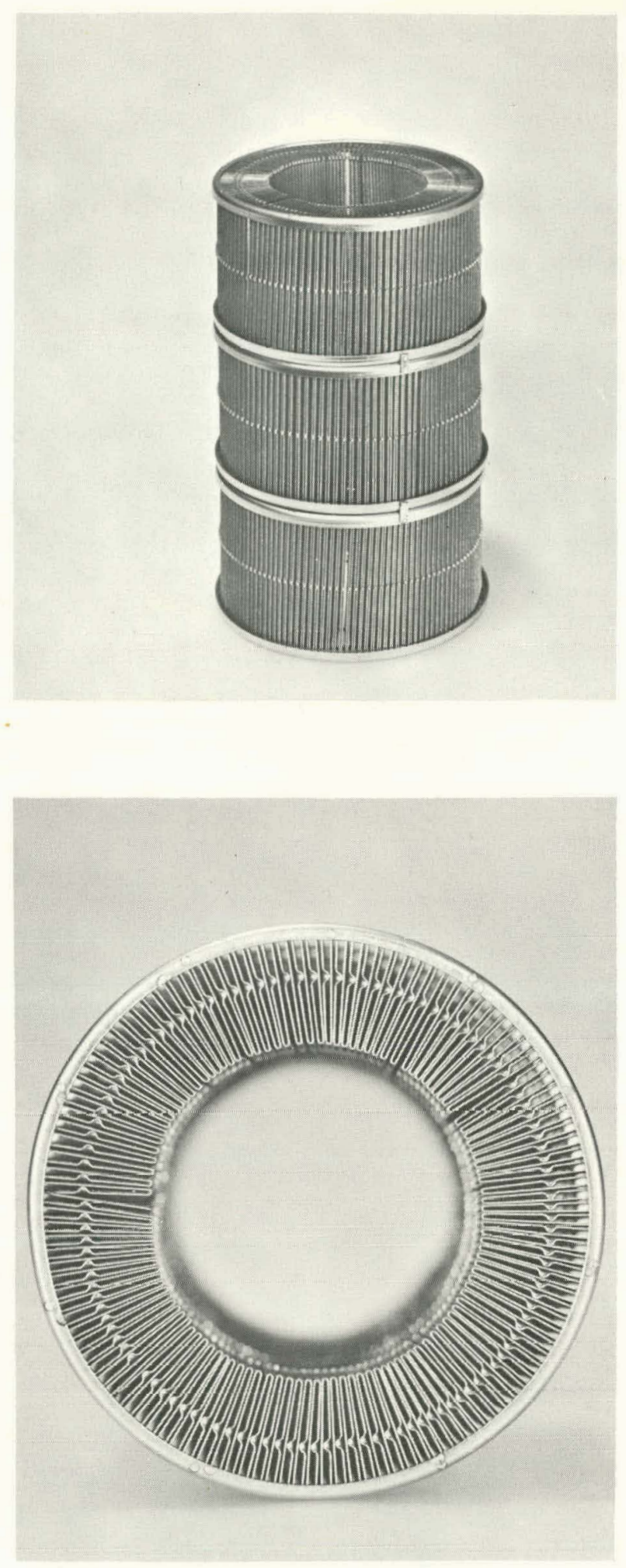

Figure 5.2-1 SAES Zr/Al Getter Cartridge 
rapidly with the carbon diffusing into the tungsten and the hydrogen being released. The $\mathrm{Zr} / \mathrm{Al}$ getter then pumps the hydrogen.

In comparing conditions for hydrogen pumping in TFTR, we have assumed that there would be $\sim 8 \mathrm{~Pa} \mathrm{~m}^{3}$ of hydrogen isotopes introduced per pulse. This gas would be pumped by a total of 16 C-500 cartridges (4 foreline cannisters, each containing four C-500 cartridges). Reduced to gas load per pulse per unit area of getter, this corresponds to $\sim 0.4 \mathrm{~Pa} \mathrm{~m} / \mathrm{m}^{2}$ per pulse. In our laboratory experiments with the small pumps we have used 50 times this dosage, $20 \mathrm{~Pa} \mathrm{~m} / \mathrm{m}^{2}$ per pulse, and find the getters work as desired at room temperature in "pure" hydrogen. Also, our experiments have used $8 \mathrm{~Pa}$ as the $\mathrm{H}_{2}$ fill-pressure in the $0.020-m^{3}$ volume in which a getter is located in order to simulate the expected maximum fore pressure of $8 \mathrm{~Pa}$ in TFTR and find them to function properly. This maximum is estimated by assuming instantaneous transfer of the $\mathrm{H}_{2}$ fill-gas to the foreline.

We have used the getters to pump much more hydrogen than the amount claimed by SAES. It was found that they can pump several times this amount even at room temperature provided the hydrogen is pure. However, there is a rise in the equilibrium pressure or the dissociation pressure. Attempts to understand the effect of impurities on the hydrogen gettering ability of the getter have been carried out. The results are as follows:

- The pumping of hydrogen with the getter at room temperature in a CO partial pressure maintained at 2.1 Pa is not observed. This is not unexpected. At room temperature the getter surface becomes saturated with $\mathrm{CO}$ under these conditions and hydrogen sorption is inhibited.

- With the getter operated at $700 \mathrm{~K}$ and exposed to a constant $\mathrm{CO}$ influx of $1.5 \mathrm{x}$ $10^{-5} \mathrm{~Pa} \mathrm{~m} / \mathrm{s}$, the hydrogen speed and capacity were greater than measured at room temperature for pure hydrogen. At $583 \mathrm{~K}$ the speed and capacity were the same at $700 \mathrm{~K}$, while unsatisfactory performance occured when the getter temperature was further decreased to $473 \mathrm{~K}$.

- An experiment using methane at a constant pressure of $2 \mathrm{~Pa}$ and a getter at $583 \mathrm{~K}$ showed the $\mathrm{H}_{2}$ speed and capacity to be unaffected.

- While the getter was at 583K, CO was pumped but methane was not. 
- The cracker/getter combination is capable of rapidly removing methane. The capacity is limited by the amount of tungsten to $\sim 6 \mathrm{~Pa} \mathrm{~m} / \mathrm{g}$.

The question of impurities remains partly unanswered. The partial pressures of various gases in the foreline are difficult to predict. In spite of the foreline being constructed using ultrahigh vacuum components, one can expect the total pressure to rise to $\sim 13 \mathrm{~Pa}$ under some operating conditions and to include large quantities of $\mathrm{CO}, \mathrm{CH}_{4}$, and $\mathrm{H}_{2} \mathrm{O}$, in addition to gas from the spent plasma. Further evaluation of these getters is proceeding to determine their ability to perform as required in TFTR in the presence of expected impurity gases, including vapors from a mechanical pump. The reason for the latter is that in the case of an accidental exposure of the foreline to such vapors, the subsequent removal of all traces of vapor is unlikely. At present it appears that the getters will be required to run at a temperature well above room temperature, e.g. , $\geq 583 \mathrm{~K}$, to maintain hydrogen pumping in the presence of chemically active gases.

\subsection{IN SITU BAKEOUT}

\subsection{Discussion}

In situ bakeout at temperatures in the range 475 to $775 \mathrm{~K}$ is generally considered to be an integral step in ultrahigh vacuum processing. $(1,2,11)$ The reason is that by such a bake of the entire vacuum system, the outgassing rate per unit area of surface exposed to the vacuum can be decreased by orders of magnitude, for example, from $10^{-7}$ to $10^{-11}$ $\mathrm{Pa} \mathrm{m}^{3} / \mathrm{s} \mathrm{m}^{2}$ or less. Usually this is the most expeditious route to obtaining very low pressures. An alternative is to provide orders of magnitude more pumping speed, but this approach is impractical or even physically impossible. The in situ bake provides a means for rapid desorption of gas which otherwise slowly "bleeds" out. It also removes low vapor pressure organics which are present as a result of inadequate cleaning processes or any lack of care in assembly of the system. When a system is known to be scheduled 
for bakeout, the requirement is automatically imposed that all materials be of ultrahigh vacuum quality to be compatible with the processing. This can be an important factor in a large device in which many experimenters are involved.

The argument for bakeout in situ of a total vacuum system is primarily directed toward attainment of a low base pressure. In the case of the TFTR, the base pressure per se is not the prime concern, rather it is the condition of the walls, especially those which are "seen" by the plasma. While pioneering the use of ultrahigh vacuum technology in plasma physics and CTR devices, PPPL has found that following ultrahigh vacuum technique but omitting the in situ bake can be a satisfactory approach based on experimental results. Thus, the TFTR conceptual design does not include bakeout. Since such a process is still under study, the following is a presentation of a method of reaching bakeout temperatures. and a summary of the various problems that must be considered if bakeout is incorporated as the design is finalized.

\subsection{A Method of Reaching Bakeout Temperatures}

One method of achieving the bakeout temperature is to induce.a. low-current discharge at a high repetition rate in a low strength steady state toroidal field. The discharges will terminate by going unstable. Assuming $200 \mathrm{~kJ}$ are deposited in the walls of the vacuum vessel per pulse for a pulse every second, the average heating rate will be $200 \mathrm{~kW}$. At this heating rate it can be shown that:

- In 3 hours the temperature will rise to $459 \cdot \mathrm{K}$

- In 5 hours the temperature will rise to $516 \mathrm{~K}$

It was assumed that there is no insulation on the vacuum vessel and that the vessel is cooled by natural convection. With insulation covering the vacuum vessel the temperature should reach $525 \mathrm{~K}$ in a reasonably short time. 
The TF coils can be run steady-state at a level that will produce $\sim 0.8 \mathrm{~T}$ at the center of the vacuum vessel. Discharges of $\sim 200 \mathrm{kA}$ should be produced for cleaning or heating purposes.

In initiating these discharges, conditions must be the same as for normal operation. In particular the plasma voltage induced by the ohmic heating winding during the first few milliseconds must be $\geq 150 \mathrm{~V}$. The discharge time could be rather short. About $10 \mathrm{~ms}$ is required to roach $200 \mathrm{kA}$, and the pulse may last for a total of $\leq 50 \mathrm{~ms}$. .

There are two comments that should be made concerning this form of heating. First, during the heating phase the pressure in the vacuum vessel will not be low, as is normal during a bakeout. Thus a heating pulse followed by a pumping phase may be required. An inert gas would probably be desirable for this application, although hydrogen discharges can be useful in reducing the carbon impurity. Second, considering all of the appendages including the neutral beam arms that would require heating, an auxilliary system is necessary if a complete in situ bakeout is to be achieved.

\subsection{Problems Related to In Situ Bakeout}

The conceptual design of the TFTR has been based on the assumption that the individual components of the vacuum vessel will be pre-baked. But there would be no in situ bakeout of the complete device. If the in situ bakeout is required, various aspects of the device design must be reexamined. In particular, the outside radius of the vessel can be expected to grow by $1.7 \mathrm{~cm}$. This was estimated for an expansion coefficient of annealed SS of 1.9 . $\times 10^{-5} \mathrm{~K}^{-1}$, an outside major radius of $3.85 \mathrm{~m}$, and a temperature change of $230 \mathrm{~K}(523 \mathrm{~K}-$ $293 \mathrm{~K}$ ). The expected problem areas of most concern are listed as follows. 


\subsubsection{Expansion Related Problems}

- The outside diameter of the vacuum vessel will grow by $3.4 \mathrm{~cm}$.

- A great deal of stress analyses would be required as a result of this thermal expansion.

- The rail support system for the torus must be modified to allow for the resulting radial motion.

- A scheme will be needed to keep the vacuum vessel centered during expansion and contraction since it would be very undesirable to have the vessel "walk" as a result of expansion and contraction.

- Differential expansion between the vacuum vessel and the vessel shield may cause deformation problems.

- : Expansion gaps designed to minimize radiation leakage will be needed around vacuum vessel appendages where they pass through the vessel and coil shields.

- The diameter of line-of-sight diagnostic tubes should be reduced to maintain adequate clearance between the tubes and the ohmic heating and equilibrium field coils.

- Provisions which consider alignment problems must be made for the outward movement of the line-of-sight diagnostic tubes as the vacuum vessel expands.

- Consideration must be given to the effect of the upward movement of the vacuum vessel on diagnostics that use horizontal lines-of-sight.

- Bellows may be required for the diagnostic tubes and for the two $61 \mathrm{~cm}$ dia. diffusion pump lines. 


\subsubsection{Temperature Related Problems}

- There may be problems with lead which melts at $600 \mathrm{~K}$ and which is to be used in diagnostic collimators or in gamma shields.

- The temperature limits of materials used in the vessel and toroidal field coil shields must be examined.

- The temperature capabilities of cerium glass (radiation resistant) port windows and the associated seals must be investigated.

- Insulation will be necessary to protect the vessel shield which must be. cooled without cooling the vacuum vessel.

- Insulation could be required to heat up the vacuum vessel in an acceptably short time, so that the vessel will not return to room temperature quickly and TFTR operations will be carried out at higher temperatures.

- The vessel bellows may get so hot as a result of currents induced in the vacuum vessel that tritium will diffuse through the bellows faster than at room temperature requiring the region outside the bellows to be part of the tritium system.

\subsubsection{Other Problems}

- Auxiliary heating will be required to bake out appendages.

- The clearances needed between appendages and radiation shields for the heaters and for insulation will create radiation streaming problems.

- Shutters may be needed to protect glass windows from deposition during bakeout or discharge cleaning operations.

- Two traps may be required for each diffusion pump where one is used during bakeout and then valved off during normal operations. 


\subsection{SUMMARY}

In this report, the primary considerations that went into designing the TFTR vacuum system were discussed. From the point of view of minimizing impurity levels, the system was designed using mercury diffusion pumps, pre-baked materials with low outgassing rates, and UHV metal seals. In situ bakeout of the entire system was not incorporated into the present design. Instead, discharge cleaning of the vessel will be periodically carried out to assure satisfactory vacuum conditions. From the point of view of handling tritium, regenerable $\mathrm{Zr}$ /Al getters backing mercury diffusion pumps, on-line RGA monitoring and tritium holding and cleanup (12) units have been integrated into the vacuum system. A brief description of the system is given in Section 2.

As discussed in Section 3, the system is expected to operate at a base pressure of $\leq 8 \times 10^{-6}$ $\mathrm{Pa}$, and have time constants for $\mathrm{T}_{2}$ associated with pumpout between pulses and filling equilibration of $4 \mathrm{~s}$ and $0.13 \mathrm{~s}$, respectively. For the high vacuum pumps, mercury and oil diffusion pumps, cryopumps, turbopumps, and sputter-ion pumps were considered, and mercury diffusion pumps were chosen. In this section, calculated M/e spectra for a "typical" RGA were presented. Assuming three operational conditions, the results show the distinct differences between spectra from pure $\mathrm{H}_{2}$ operation, $H-D$ operation, and D-T operation. In the TFTR forelines, typical RGA's can be expected to detect $\mathrm{T}_{2}$ at the $\mathrm{l}_{\mu} \mathrm{Ci}$ level.

The next section, Section 4, was a presentation of the criteria and selection of vacuum seals. Bakeable, UHV metal seals for general usage are assumed necessary to guarantee a specific outgassing rate for impurities below the acceptable level of $\leq 10^{-9} \mathrm{~Pa} \mathrm{~m} / \mathrm{s} \mathrm{m}^{2}$. Since there are over 400 seals and since these seals must undergo thermal cycling during pre-baking and discharge cleaning, these seals must be of a very high degree of reliability. Conflat-type seals modified with features to accommodate remote handling operations were selected over gold wire corner seals although gold seals could be used for special applications. 
The results of the experimental testing of $\mathrm{Zr} / \mathrm{Al}$ getters was presented in Section 4. The getters, made by SAES, bond the hydrogen chemically and are regenerable for at least 20 times. More testing is required, but present results show these getters to function properly at $\geq 575 \mathrm{~K}$ in vacuum systems containing levels of $\mathrm{CO}$ and $\mathrm{CH}_{4}$ expected in TFTR.

In the last section in situ bakeout was discussed in detail. Even though such an operation is not part of the present TFTR vacuum conditioning procedure, it is still considered as a design alternative. Part of Section 6 was a presentation of a method using low-current discharges at a high repetition rate as a means of achieving bakeout conditions. If such a method of bakeout were incorporated, several problem areas would require serious consideration. The final subsection enumerated these areas which include expansion related problems, temperature related problems, and problems associated with the bakeout of appendages, glass windows, and the traps above the high vacuum pumps.

In the various sections of this report important parameters associated with the TFTR vacuum system were presented. Several other important parameters related to the vacuum system but not discussed in this report have been presented in other volumes of the TFTR Conceptual Design Report. For completeness, a tabulation of all these parameters is given in Table 7.0-1. 
TABLE $7.0-1$

TABULATION OF IMPORTANT PARAMETERS FOR THE TFTR VACUUM SYSTEM

A DIMENSIONS

- Torus Vacuum Vessel

$\begin{array}{lc}\text { Major Radius } & 2.65 \mathrm{~m} \\ \text { Minor Radius } & 1.10 \mathrm{~m} \\ \text { Volume } & 64 \mathrm{~m}^{3} \\ \text { Surface Area } & 1000 \mathrm{~m}^{2}\end{array}$

- Foreline of each Diffusion Pump

$\begin{array}{lc}\text { Average Length of Piping to D. P. } & 20 \mathrm{~m} \\ \text { Pipe Diameter } & 0.1 \mathrm{~m} \\ \text { Foreline Volume } & \geq 0.16 \mathrm{~m}^{3} \\ \text { Foreline Surface Area } & \gtrsim 6.3 \mathrm{~m}^{2}\end{array}$

- Neutral Beam Ducts
Cross Section $\quad 0.46 \mathrm{~m} \times 0.72 \mathrm{~m}$
Length $\quad 0.71 \mathrm{~m}$

- Number of Penetrations through Torus Vessel $\sim 250$

- Total Area of Ports Penetrating the Torus Vessel $\sim 8 \mathrm{~m}^{2}$

- Total Length of Seals on the Vessel Ports $\quad \sim 300 \mathrm{~m}^{\prime}$

B. ESTIMATED OUTGASSING RATES IN Pa m $3 / \mathrm{s} \mathrm{m}^{2}$ (Torr liters $/ \mathrm{s} \mathrm{cm}^{2}$ )

- Torus Vacuum Vessel $<10^{-7} \quad\left(10^{-10}\right)$ for Hydrogen $\leq 10^{-9} \quad\left(10^{-12}\right)$ for Impurities

- Foreline $\leq 10^{-6} \quad\left(10^{-9}\right)$ for Air

C LEAK RATE OF $61-\mathrm{cm}$ UHV Valve above D. P. in $\leq 1.3 \times 10^{-7}\left(10^{-6}\right)$ $\mathrm{Pa} \mathrm{m} / \mathrm{s}$ (Torr liters $/ \mathrm{s}$ )

(Cont.) 


\section{TABLE 7.0-1 (Cont.)}

D TIME CONSTANTS AND TIMES IN seconds

- High-Vacuum Pump-out Time Constant

(Vessel Volume/HV Pumping Speed)

$$
1.92 \text { for } \mathrm{H}_{2}
$$

- Mechanical Pumping System Time Constant

(Vessel Volume/Total Mechanical Pumping Speed) 480 for Air

- Rough-down Time

- HV Pumpout Time Between Pulses

- Filling Equilibration Time Constant for Vacuum Vessel

E RGA PARAMETERS

- Dynamic Range of RGA

- Resolving Power of RGA (MV $\triangle M$ )

- RGA Detectability of $T_{2}$ in Foreline

- RGA Partial Pressure Sensitivity.

F PUMPING SPEEDS $I \mathrm{~N} \mathrm{~m}^{3} / \mathrm{s}$

- Each Diffusion Pump Stack

- Effective Speed of D. P. Stack on N. B. Duct $\left(16 \mathrm{~m}^{3} / \mathrm{s}\right.$

Conductiance for Air)

- Total Effective High Vacuum Pumping Speed (4 D. P. Stacks)

- Each $\mathrm{Zr} / \mathrm{Al}$ Canister (4 C.artridges)

- Each Mechanical Pump
$\$ 16200$ (4.5 hr) for Air

$\sim 18$ for $\mathrm{H}_{2}$

$\sim 25$ for $D_{2}$

$\sim 28$ for $D_{2}(50 \%)-T_{2}(50 \%)$

0.13 for $T_{2}$ $\geq 10^{6}$

$\geq 50$

$\sim 1 \mu \mathrm{Ci}$

$\geq 10^{-8} \mathrm{~Pa}$
3.1 for Air

9.0 for $\mathrm{H}_{2}$

2.6 for Air

7.5 for $\mathrm{H}_{2}$

33 for $\mathrm{H}_{2}$

10 for $\mathrm{H}_{2}$

0.033 for Air

(Cont.) 
- Base Pressure in Vacuum Vessel

- Ultimate Foreline Pressure at Diffusion Pump

- Critical Foreline Pressure for Proper Diffusion Pump Operation

- Expected Fore Pressure Risé per 8 Hour-Day of Operation Without Pumping by Mechanical Pumps

H $\quad \mathrm{Zr} / \mathrm{Al}$ CANISTER PARAMETERS (pumping speed given above)

- Capacity

- Expected Operating Temperature

- Number of Useful Regenerations

- Number of Pulses/Regéneration Each Canister

Is Expected to Operate Efficiently. $\leq 3 \times 10^{-6}\left(2.3 \times 10^{-3}\right)$ for $\mathrm{H}_{2}$

$\leq 6.7 \times 10^{-6}\left(5 \times 10^{-8}\right)$ for

$D_{2}(50 \%)-T_{2}(50 \%)$

$\leq 8 \times 10^{-6}\left(5.6 \times 10^{-8}\right)$ for $\mathrm{T}_{2}$ $\leq 1.3\left(10^{-2}\right)$ for Air

$67(0.5)$ for Air or $\mathrm{H}_{2}$

$80(0.6)$ for $0.08 \mathrm{~Pa} \mathrm{~m}^{3}$ of Impurities per pulse $\sim 2000 \mathrm{~Pa} \mathrm{~m}^{3}$ of Hydrogen

$575 \mathrm{~K}$

$\geq 20$

$\sim 1000$ 


\section{References}

1. Donald J. Santeler, Donald W. Jones, David H. Holkeboer and Frank Pagano, "Vacuum Technology and Space Simulation", (NASA document, U.S. Government Printing Office, Washington, DC, 1966) pp. 234-266.

2. Examples: M. A. Steinherz "Handbook of High Vacuum Engineering," (Reinhold Publishing Corp, New York, 1963); P. A. Redhead, J. P. Hobson, and E. V. Kornelsen, "The Physical Basis of Ultrahigh Vacuum", (Chapman and Hall, Ltd, London, 1968).

3. Examples: John J. Sullivan, and John B. Schultz, "Design Parameters for Inert Gas Welding and Vacuum Brazing of Vacuum Components: (Technical Report ECOM2651, Defense Documentation Center, Alexandria, VA, 1965); Virgil A. Wright, Jr., "Stainless Steel for Ultra-high Vacuum Applications", (Report VR-39, Varian Associates, Vacuum Division, Palo Alto, California)

4. Trademark of Varian Associates, Palo Alto, California. Similar \& interchangeable flanges sold under other names or trademarks are available from most manufacturers of vacuum components in the U.S.A.

5. American Vacuum Society, Ine. Committee on Standards (in process).

6. The gold wire corner seal apparently evolved before 1950 in several laboratories. The best storehouse of design and use information probably resides with the vacuum group of PPPL; see also G. Lewin, "Fundamentals of Vacuum Science and Technology", (McGraw-Hill, New York, 1965).

7. W. R. Wheeler, and M. Coulson, "Ultra-high Vacuum Flanges", Trans. of the $8^{\text {th }}$ National Vacụum Symposium, Pergaman Press, Inc. (1962), p. 1309. 
8. W. R. Wheeler, "Theory and Application of Metal Gasket Seals," Trans. of the 10" National Vacuum Symposium; The Mac Millan Co., )1963), p. 159.

9. W. R. Wheeler, Varian Associates, private communication, June 1975.

10. SAES Getters/USA, Buffalo, New York.

11. L. C. Beavis, J. Vac. Sci. and Technol. 10, 386 (1973); R. Calder and G. Lewin, Br. J. Appl. Phys. 18, 1459 (1967).

12. H. J. Garber, Proceedings of the International Conference on Radiation Effects and Tritium Technology for. Fusion Reactors, October 1-3, 1975, Gatlinburg, Tenn., to be published, also see Westinghouse Technical Report WFPS-TME-005, September, 1975. 